\title{
Coupled atmosphere-mixed layer ocean response to ocean heat flux convergence along the Kuroshio Current Extension
}

\author{
Young-Oh Kwon · Clara Deser • Christophe Cassou
}

Received: 30 October 2009/ Accepted: 8 February 2010/Published online: 25 February 2010

(C) Springer-Verlag 2010

\begin{abstract}
The winter response of the coupled atmosphere-ocean mixed layer system to anomalous geostrophic ocean heat flux convergence in the Kuroshio Extension is investigated by means of experiments with an atmospheric general circulation model coupled to an entraining ocean mixed layer model in the extra-tropics. The direct response consists of positive SST anomalies along the Kuroshio Extension and a baroclinic (low-level trough and upper-level ridge) circulation anomaly over the North Pacific. The low-level component of this atmospheric circulation response is weaker in the case without coupling to an extratropical ocean mixed layer, especially in late winter. The inclusion of an interactive mixed layer in the tropics modifies the direct coupled atmospheric response due to a northward displacement of the Pacific Inter-Tropical Convergence Zone which drives an equivalent barotropic anomalous ridge over the North Pacific. Although the tropically driven component of the North Pacific atmospheric circulation response is comparable to the direct response in terms of sea level pressure amplitude,
\end{abstract}

Electronic supplementary material The online version of this article (doi:10.1007/s00382-010-0764-8) contains supplementary material, which is available to authorized users.

Y.-O. Kwon $(\bowtie)$

Physical Oceanography Department,

Woods Hole Oceanographic Institution,

Clark 320A, MS\#21, Woods Hole, MA 02543, USA

e-mail: yokwon@whoi.edu

C. Deser

National Center for Atmospheric Research,

Boulder, CO, USA

C. Cassou

CNRS-CERFACS, Toulouse, France it is less important in terms of wind stress curl amplitude due to the mitigating effect of the relatively broad spatial scale of the tropically forced atmospheric teleconnection.

\section{Introduction}

Various observational studies indicate that decadal-scale sea surface temperature (SST) variations along the Kuroshio Current Extension result from geostrophic ocean circulation changes in response to basin-scale wind stress curl fluctuations 3-5 years earlier (Miller et al. 1998; Deser et al. 1999; Xie et al. 2000; Qiu 2000; Seager et al. 2001; Schneider and Miller 2001; Vivier et al. 2002; Qiu 2003; Kelly 2004). The circulation-induced SST anomalies in turn alter the local air-sea energy exchange, in particular the surface turbulent energy fluxes in winter (Seager et al. 2001; Tanimoto et al. 2003; Kelly 2004). The nature of the atmospheric response to the surface energy flux anomalies remains difficult to discern from observations alone, however, due to the high levels of internal and tropically forced atmospheric variability (Qiu et al. 2007; Frankignoul and Sennéchael 2007).

Some coupled general circulation (Pierce et al. 2001; Kwon and Deser 2007; Zhong et al. 2008) and observationally based analytical (Qiu et al. 2007) modelling studies suggest that ocean-atmosphere interaction within the North Pacific can sustain decadal-scale oscillations. In these studies, the response of the large-scale atmospheric circulation to SST anomalies induced by ocean heat transport variations along the western boundary currents is a key component. In particular, the strength and pattern of the atmospheric circulation response to the extra-tropical SST anomalies determines whether such decadal-scale variability is a result of mutual coupling between the ocean 
and atmosphere (Latif and Barnett 1996; Neelin and Weng 1999; Pierce et al. 2001; Wu and Liu 2005; Kwon and Deser 2007; Zhong and Liu 2009) or an internal mode of the ocean (Frankignoul et al. 1997; Saravanan and McWilliams 1998; Cessi and Primeau 2001; Qiu 2003; Berloff et al. 2007).

The tropics may also play a role in initiating decadalscale variability over the North Pacific (Newman et al. 2003; Vimont 2005; Schneider and Cornuelle 2005; Alexander 2010). In particular, the El Nino/Southern Oscillation (ENSO) phenomenon has been suggested to contribute to the Pacific Decadal Oscillation (PDO), defined as the leading mode of SST variability in the North Pacific (Mantua et al. 1997; Zhang et al. 1997), via atmospheric teleconnections and the thermal response of the deep winter ocean mixed layer in the North Pacific (Newman et al. 2003; Vimont 2005). These ENSO-based reconstructions of the PDO, however, do not fully account for the decadal-scale SST variations along the Kuroshio Extension. Schneider and Cornuelle (2005) showed that additional oceanic processes are needed to explain the low-frequency component of SST variability along the Kuroshio Extension. In particular, westward propagating baroclinic Rossby waves driven by ENSO-induced wind stress curl fluctuations in the central and eastern North Pacific contribute to SST anomalies along the Kuroshio Extension via changes in vertical mixing and heat transport. Although the tropics play an important role in generating decadal-scale SST variability over the North Pacific (i.e., the PDO), feedbacks from the ocean to the atmosphere within the North Pacific may also contribute.

It is clear from the issues outlined above that a better understanding of the atmospheric response to ocean circulation-induced SST anomalies along the Kuroshio Extension would advance understanding of decadal climate variability over the North Pacific. A common approach to this problem has been to use an atmospheric general circulation model (AGCM) forced with prescribed SST anomalies; however, the results diverge greatly among different studies (see the review by Kushnir et al. 2002). Progress made in the past decade suggests that the diverse equilibrium atmospheric responses among different SSTspecified AGCM studies can be attributed in part to differing sensitivity of transient eddy feedbacks (Peng et al. 1997; Peng and Whitaker 1999) and structure of the models' internal variability (Peng and Robinson 2001; Deser et al. 2004). Linear model studies predict downstream low pressure anomalies at sea-level with a baroclinic vertical structure in response to shallow positive diabatic heating anomalies (Hoskins and Karoly 1981; Hendon and Hartmann 1982). This so-called "warm-low" equilibrium response is associated with an anomalous northerly low-level wind balancing the imposed anomalous diabatic heating. However, nonlinear transient eddy feedbacks may substantially modify the linear response and produce an equivalent barotropic downstream high response (e.g. Peng and Whitaker 1999; Deser et al. 2007).

Several recent studies have noted the limitation of AGCM experiments with specified SST anomalies (e.g. Kumar and Hoeling 1998; Bretherton and Battisti 2000; Yulaeva et al. 2001; Sutton and Mathieu 2002). The experiments in which SSTs are not allowed to respond to changes in atmospheric circulation can produce misleading results, since the SST anomalies should result from the imbalance between the net heat flux across the air-sea interface and the lateral convergence of heat into the ocean mixed layer.

One way to provide a more realistic assessment of the ocean's role in climate variability is to use a model configuration in which the atmosphere is coupled to an ocean mixed layer with prescribed ocean heat transport variations due to dynamical processes not included in the ocean mixed layer model. In this configuration, SST and surface heat flux anomalies reflect to a greater degree the true twoway coupling between the atmosphere and the ocean mixed layer. Two pioneering studies, one for the North Pacific (Yulaeva et al. 2001) and the other for the North Atlantic (Sutton and Mathieu 2002), have applied this approach. Both studies used idealized forms of ocean heat flux convergence (OHFC) anomalies, and both employed AGCMs coupled to a non-entraining slab ocean mixed layer model for their 10-year long integrations. The winter atmospheric circulation response in the study of Yulaeva et al. (2001) consisted of an equivalent barotropic low downstream of anomalously warm SST induced by lateral OHFC in the Kuroshio Extension. Sutton and Mathieu (2002) also reported a downstream equivalent barotropic low pressure response to anomalous OHFC in the Gulf Stream region.

Liu and $\mathrm{Wu}$ (2004) compared four approaches for investigating the atmospheric response to SST anomalies in the Kuroshio Extension region: (1) specified SST anomalies in an AGCM, (2) specified surface air-sea heat flux anomalies in an AGCM, (3) specified ocean temperature anomalies in the upper $200 \mathrm{~m}$ as initial conditions to a fully coupled ocean-atmosphere GCM, and (4) as in (3) but allowing only thermal coupling. The specified SST anomaly experiment produced a downstream equivalent barotropic high-pressure response to a positive SST anomaly, while the air-sea heat flux anomaly experiment produced a downstream equivalent barotropic low response. The fully coupled experiment produced an equivalent barotropic high pressure response which they concluded was a combination of the responses in cases (1) and (2) above. The thermally coupled experiment produced a similar response to that of the fully coupled experiment but with about half the magnitude. Like the specified SST 
experiment, the specified surface air-sea heat flux experiment is limited in the sense that the forcing does not result from an imbalance between the heat flux convergences in the lower atmosphere and upper ocean. Thus, the surface air-sea heat flux specified experiments are not necessarily equivalent to the simulations in Sutton and Mathieu (2002) and Yulaeva et al. (2001) who specified the lateral OHFC anomalies and allowed both SSTs and the surface air-sea heat fluxes to be determined prognostically. On the other hand, the thermally coupled experiment with initial upper ocean temperature anomalies is more in line with the experimental design of Sutton and Mathieu (2002) and Yulaeva et al. (2001).

A subsequent study by Liu et al. (2007) explored further the fully coupled model approach, specifying an initial distribution of upper ocean temperature anomalies in the Kuroshio Extension and examining the subsequent transient coupled response over a 4-year period. They found that the atmospheric circulation response for early and late winter differ considerably, as in Peng et al. (1997). In November-January, the warm SST anomalies are accompanied by an equivalent barotropic ridge over the North Pacific and downstream wave train resembling the PacificNorth American (PNA) pattern (Wallace and Grutzler 1981). On the other hand, the atmospheric response in February-April is significantly weaker than that in November-January, with a baroclinic warm-low structure. They briefly speculated that the distinctive responses in early and late winter may be due to the different background atmospheric states as suggested by Peng et al. (1997).

Kwon and Deser (2007) analyzed decadal variability in the North Pacific from a 650-year control integration of Community Climate System Model version 2 (CCSM2), a coupled general circulation model. They found that the wind stress curl response to ocean circulation-induced SST variations in the Kuroshio Extension played a key role in sustaining quasi-decadal (15-20 year) coupled atmosphere-ocean oscillations. Specifically, positive wind stress curl anomalies in the latitude band $30^{\circ}-50^{\circ} \mathrm{N}$ occur in response to positive SST anomalies along the Kuroshio Extension. This response in turn implies subsequent development of negative SST anomalies in the Kuroshio Extension due to oceanic Rossby wave adjustments, i.e. a negative feedback. The wind stress curl response diagnosed in Kwon and Deser (2007) was determined empirically using lag regression analysis, supplemented with preliminary results from additional atmospheric modeling experiments. A summary of the various studies cited above is given Table 1 .

The purpose of this study is to provide a more comprehensive assessment of the atmospheric circulation response to OHFC anomalies in the Kuroshio Extension using a broader suite of modeling experiments than in Kwon and Deser (2007). In particular, we systematically compare the responses using the standard "specified SST" approach with the alternative "specified OHFC" approach. In order to understand the atmospheric response in the fully coupled system of CCSM2, we retain the component models of CCSM2 as much as possible to ensure consistency between the CCSM2 and the simplified experiments. Specifically, we employ the atmospheric model component of CCSM2 for the "specified SST" experiments, and a simplified coupled model consisting of the atmospheric model component of CCSM2 coupled to an entraining ocean mixed layer model for the "specified OHFC" integrations. The OHFC anomalies along the Kuroshio Extension diagnosed from the CCSM2 are prescribed in the simplified coupled model experiments. The resulting SST anomalies are then specified in the atmospheric GCM experiments. Interaction of the atmospheric response over the North Pacific with the tropics is also examined in an idealized setting by comparing the results from the simplified coupled model experiments with and without an interactive tropical ocean mixed layer. Section 2 describes the model and experiment design. Results are presented in Sect. 3 and discussed in Sect. 4. Conclusions are presented in Sect. 5.

\section{Model experiments}

\subsection{Coupled model: CMLM}

The coupled model used in this study consists of an atmospheric general circulation model, a mixed layer ocean model, a thermodynamic sea-ice model and a land model (Cassou et al. 2007). The coupled model has almost identical atmospheric and land components as the CCSM2 (Kiehl and Gent 2004), while the ocean component is greatly simplified, and the sea-ice component retains only the thermodynamic portion of that in CCSM2. The atmospheric component model is the Community Atmospheric Model version 2 (CAM2) (Kiehl and Gent 2004), which has T42 horizontal resolution (=about $2.8^{\circ}$ latitude by $2.8^{\circ}$ longitude) and 26 vertical levels using a hybrid coordinate. The land surface and the sea-ice components are the Community Land Model (CLM2) (Bonan et al. 2002) and the thermodynamic component of the Community Sea-Ice Model (CSIM4) (Briegleb et al. 2004), respectively. Ocean, sea-ice, and land models are all aligned with the atmospheric model grid.

The ocean component is an entraining mixed layer model (MLM), which is an array of independent single column multi-layer models with explicit mixed layer physics. The mixed layer depth (MLD) is calculated 


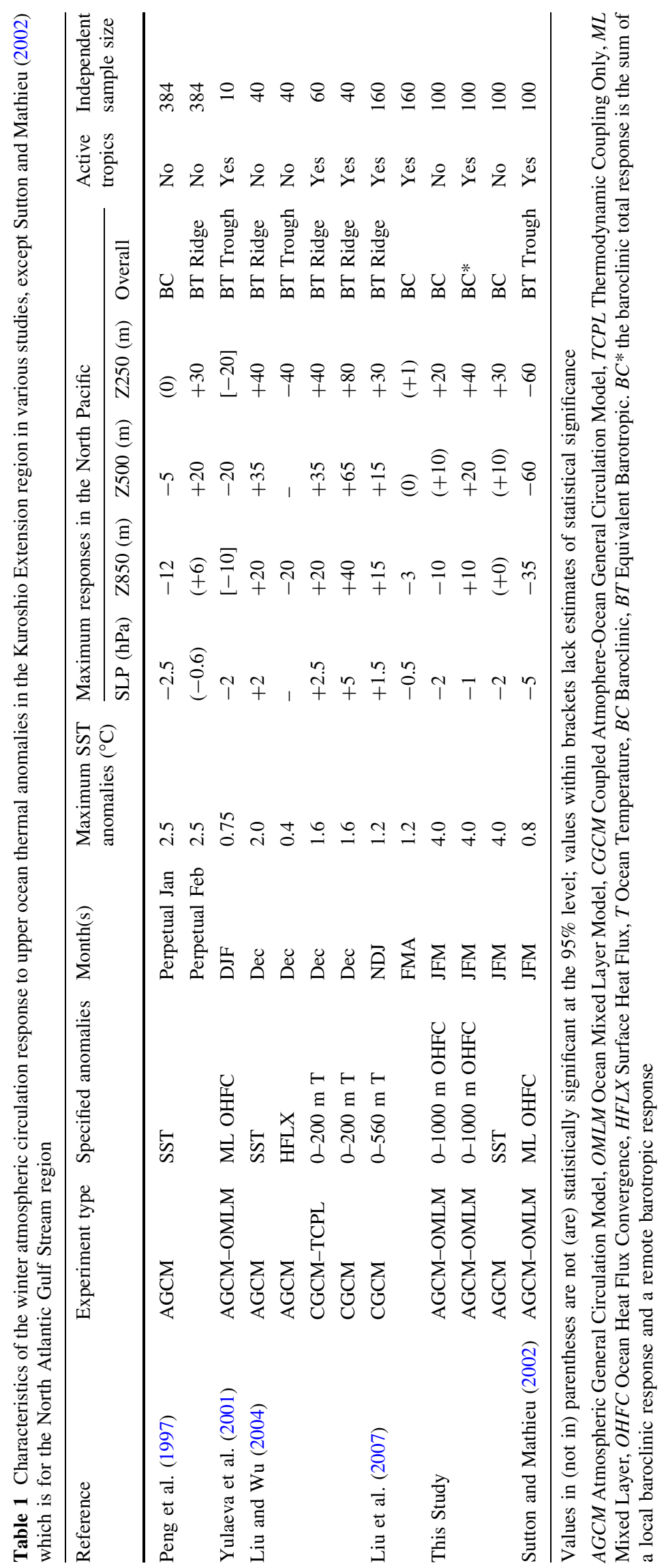


prognostically for each time step based on Gaspar (1988)'s formulation as implemented by Alexander and Deser (1995). In the present study we use a version of the MLM modified by Cassou et al. (2007) which has 36 vertical layers in the upper $1500 \mathrm{~m}$ with 15 layers in the upper $100 \mathrm{~m}$. The MLM allows us to specify the OHFC anomalies into multiple vertical layers of the upper ocean and also to examine the role of entrainment.

The climatological mean surface heat flux correction and salt flux correction are applied to account for missing physics in the MLM such as ocean heat transport by the mean currents and diffusion, as well as the model biases in the surface fluxes at the atmosphere-ocean boundary to a lesser extent. Note that Ekman transport is not included in the version of MLM used in this study. Hereafter, the coupled model is referred as CMLM. The reader is referred to Cassou et al. (2007) for further description of the CMLM.

\subsection{CMLM control integration}

The 150-year control integration of CMLM (hereafter CMLM-C) from Cassou et al. (2007) is used as a baseline experiment for comparison with the perturbation integrations. The control integration, with the inclusion of flux corrections, produces a reasonable climatology as assessed in detail by Cassou et al. (2007). The main deficiency of the CMLM is the weaker year-to-year variability of SST over the North Pacific compared to that in CCSM2 and observations (maximum rms values $\sim 0.5^{\circ} \mathrm{C}$ in CMLM compared to $0.8^{\circ} \mathrm{C}$ in $\mathrm{CCSM}$ and $0.9^{\circ} \mathrm{C}$ in observations, excluding the region directly east of Japan). This may be due in part to the absence of lateral ocean dynamics in the MLM. Atmospheric variability is well simulated in CMLM compared to observations and CCSM2, including the intensity and location of the storm track over the North Pacific. The reader is referred to the web supplement (http://www.cgd.ucar.edu/cas/cdeser/CMLM_supfig.html) for comparisons among observations and the CMLM and CCSM2 control integrations.

\subsection{CMLM perturbation integrations}

To investigate the coupled atmosphere-ocean mixed layer response to ocean heat transport variations, perturbation experiments are designed with additional geostrophic $\mathrm{OHFC}$ anomalies in the Kuroshio Extension $\left(35^{\circ}-45^{\circ} \mathrm{N}\right.$, $140^{\circ} \mathrm{E}-180^{\circ}$ ) specified in the upper $1000 \mathrm{~m}$ of the CMLM. Two 100-year long perturbation integrations are performed with identical design except for the treatment of the tropical oceans. The first perturbation integration, which is our primary experiment, has the interactive MLM only in the extra-tropics (north of $20^{\circ} \mathrm{N}$ and south of $20^{\circ} \mathrm{S}$ ) to isolate the direct response to the local anomalous OHFC forcing in the North Pacific. The climatological mean SST from the CMLM-C is specified in the tropics. The additional perturbation integration has the interactive MLM over the entire global ocean including the tropics. Hereafter, the first and second perturbation integrations are referred as CMLM-E and CMLM-G, respectively, where E stands for extra-tropics and $\mathrm{G}$ stands for global.

The geostrophic OHFC anomalies are diagnosed from the years 350-999 of the CCSM2 control integration (Kwon and Deser 2007). The anomalies for each month are calculated as the root-mean-square of 10-year low-pass filtered time series of the corresponding month's geostrophic OHFC. For example, January values for the 650year period are first 10-year low-pass filtered and then the root-mean-square of the filtered time series is assigned as the January anomaly. The 10-year low-pass filter is applied to obtain typical amplitudes of the decadal variability. The anomalies are calculated independently for each (longitude, latitude, depth) point. Then the repeating annual cycle of the anomalies are specified in CMLM. The Ekman OHFC has been removed from the total OHFC to retain only the geostrophic component, where we have assumed that the total Ekman OHFC is distributed uniformly throughout the mixed layer.

The distribution of specified geostrophic OHFC anomalies in the upper $10 \mathrm{~m}$ in March is shown in Fig. 1a. Values are about $4.2 \mathrm{~W} \mathrm{~m}^{-2}$ on average in the Kuroshio Extension, with maximum amplitudes up to $15 \mathrm{~W} \mathrm{~m}^{-2}$ along $40^{\circ} \mathrm{N}$ near the coast of Japan. Note that we have specified only geostrophic OHFC anomalies in the domain confined to the Kuroshio Extension $\left(35^{\circ}-45^{\circ} \mathrm{N}, 140^{\circ} \mathrm{E}-\right.$ $180^{\circ}$ ) to ensure an appropriate oceanic forcing based on the analysis of CCSM2 by Kwon and Deser (2007). Spatial distributions in March are representative of those throughout the year with modulation of amplitude as shown in Fig. 1b. The average anomalies in the upper $10 \mathrm{~m}$ are maximum in February $\left(=4.6 \mathrm{~W} \mathrm{~m}^{-2}\right)$ and minimum in September $\left(=2.2 \mathrm{~W} \mathrm{~m}^{-2}\right)$. The geostrophic OHFC anomalies have significant magnitude beneath the climatological mean MLD (shown as the dashed lines in Fig. 1b-d). The vertical sections along $40^{\circ} \mathrm{N}$ and $150^{\circ} \mathrm{E}$ show maximum amplitudes at the surface along $40^{\circ} \mathrm{N}$ near the coast of Japan and a gradual decrease with depth and distance from the maximum amplitude region (Fig. 1c, d).

A few observational estimates of geostrophic OHFC anomalies have been reported against which our estimates from CCSM2 may be compared. Qiu (2000) estimated January-March average non-seasonal geostrophic OHFC anomalies in the Kuroshio Extension to be about $5 \times$ $10^{-8 \circ} \mathrm{C} \mathrm{s}^{-1}$. Qiu (2000) estimate is based on the surface geostrophic velocity from sea surface height measurements of satellite altimetry during 1993-1999. Vivier et al. (2002) 
(a)

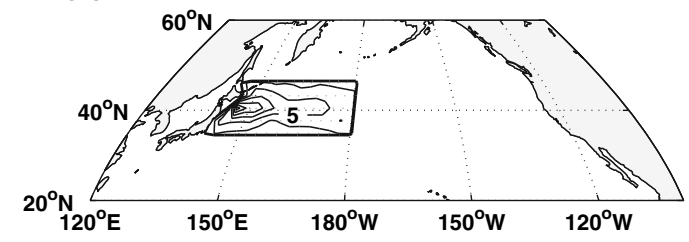

(c)

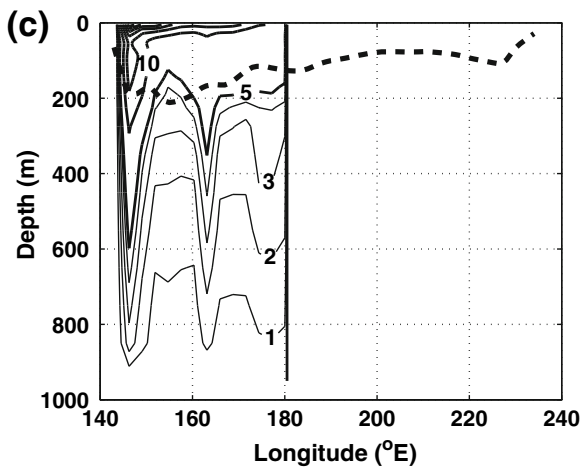

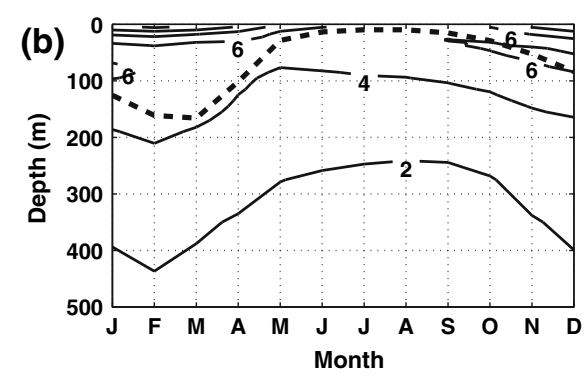

(d)

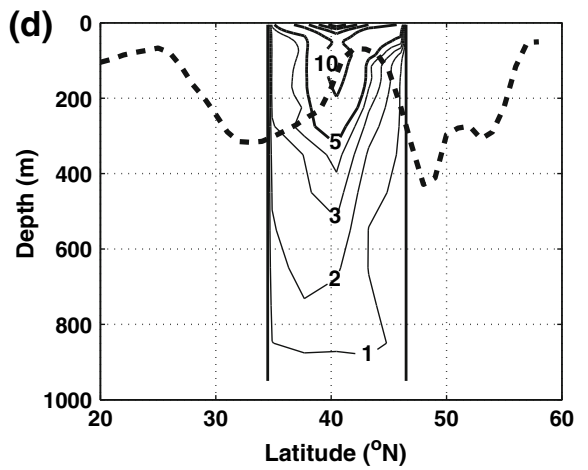

Fig. 1 Geostrophic ocean heat flux convergence anomalies for the CMLM perturbation integrations. a Map of March values integrated over upper $10 \mathrm{~m}$. Contour interval is $2.5 \mathrm{~W} \mathrm{~m}^{-2}$. b Values averaged over the Kuroshio Extension region $\left(35^{\circ}-45^{\circ} \mathrm{N}, 140^{\circ} \mathrm{E}-180^{\circ}\right)$ as a function of month and depth, expressed as a temperature tendency $\left({ }^{\circ} \mathrm{C} \mathrm{s}^{-1}\right)$. Contour interval is $2 \times 10^{-8}{ }^{\circ} \mathrm{C} \mathrm{s}^{-1}$. Dashed line indicates

estimated non-seasonal lateral (geostrophic + Ekman) OHFC anomalies in the Kuroshio Extension to be about

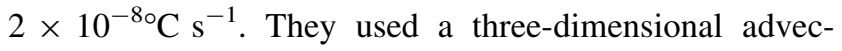
tion-diffusion ocean model with specified geostrophic and Ekman velocities estimated from satellite altimetry measurements and wind stress from the NCEP-NCAR Reanalysis (Kalnay et al. 1996). By assimilating observed SST and subsurface temperature data into a simple upper-ocean mixed layer model for 1970-2000, Kelly (2004) estimated non-seasonal root-mean-square of lateral OHFC anomalies in the Kuroshio Extension and its recirculation gyre to be $9 \mathrm{~W} \mathrm{~m}^{-2}\left(\sim 0.8 \times 10^{-8 \circ} \mathrm{C} \mathrm{s}^{-1}\right)$ for the upper $300 \mathrm{~m}$. Both Vivier et al. (2002) and Kelly (2004) estimates are not just for the winter months, but for the entire year. Thus, the geostrophic OHFC anomalies from CCSM2 are consistent with, albeit somewhat larger than, previous estimates based on the available observations.

The equilibrium responses of CMLM-E and CMLM-G are examined by computing the differences between the mean of the 100-year perturbation integrations and the mean of the 150-year control integration CMLM-C. The first 10 years (5 years) of the CMLM-E and CMLM-G (CMLM-C) integrations are excluded due to spin-up effects. The 95\% statistical significance level of the response is assessed using a Student's $t$ test. Each year is considered as independent, so that the perturbation integrations and the control integration are considered as the climatological monthly mean mixed layer depth (MLD) from the CCSM2 control integration. $\mathbf{c}$ Vertical section of March values along $40^{\circ} \mathrm{N}$. Contour interval is $5 \times 10^{-8 \circ} \mathrm{C} \mathrm{s}^{-1}$ and $1 \times 10^{-8}{ }^{\circ} \mathrm{C} \mathrm{s}^{-1}$, for the thick and thin solid contours, respectively. Dashed line indicates the March climatological mean MLD from the CCSM2 control integration. d Same as c, but along $150^{\circ} \mathrm{E}$

ensembles of 100 and 150 members, respectively. The robustness of the response is also evaluated by comparing sub-samples of the model output (e.g., first vs. second half, odd vs. even years). Overall, consistent results are found for the sub-sampled years (not shown). Note that the perturbation integrations are 100 years in length in order to enhance the signal to noise ratios of the responses, not to simulate the decadal-scale variability found in the CCSM2 coupled general circulation model.

\subsection{Specified SST experiments}

In addition to the coupled model experiments, we have conducted specified SST experiments with CAM2 using SSTs from the CMLM experiments. This SST-specified configuration is the traditional method for examining the atmospheric response to SST anomalies as discussed above. To ensure an appropriate comparison with the response in CMLM-E to the anomalous OHFC, a 150-year stand-alone CAM2 control integration (hereafter AGCMC) is first performed with climatological mean annual cycle of SST and sea-ice concentration from the CMLM-C specified as the boundary condition. The annual cycle of the equilibrium SST responses of CMLM-E in the Kuroshio Extension $\left(35^{\circ}-45^{\circ} \mathrm{N}, 140^{\circ} \mathrm{E}-180^{\circ}\right)$ is then added as anomalies to the SST boundary condition of AGCM-C in another 100-year stand-alone CAM2 perturbation 
Table 2 Summary of the simulations used in this study

\begin{tabular}{llll}
\hline Experiment name & Specified perturbation & Mixed layer ocean & Length of integration (years) \\
\hline CMLM-C & None & Global & 150 \\
CMLM-E & OHFCA within KE from CCSM2 & Poleward of 20N,S & 100 \\
CMLM-G & OHFCA within KE from CCSM2 & Global & 100 \\
AGCM-C & None & None & 150 \\
AGCM-E & SSTA within KE from CMLM-E & None & 100 \\
\hline
\end{tabular}

$\mathrm{KE}$ and OHFCA refer to the Kuroshio Extension $\left(35^{\circ}-45^{\circ} \mathrm{N}, 140^{\circ} \mathrm{E}-180^{\circ}\right)$ and the ocean heat flux convergence anomalies, respectively

integration (hereafter AGCM-E). The equilibrium response for the stand-alone CAM2 perturbation integration is assessed following the same method as the CMLM perturbation integrations. All five integrations used in this study are summarized in Table 2.

\section{Results}

\subsection{CMLM-E experiment}

We will begin with the results from the CMLM-E experiment to describe the responses most directly driven by North Pacific OHFC anomalies. The annual cycles of the responses within the forcing region $\left(35^{\circ}-45^{\circ} \mathrm{N}, 140^{\circ} \mathrm{E}-\right.$ $180^{\circ}$ ) are presented in Fig. 2. Ocean temperatures increase throughout the water column as a direct response to the specified anomalous OHFC. Maximum temperature anomalies are found around $300 \mathrm{~m}$, although the specified anomalous OHFC is largest near the surface (Fig. 1b). The maximum warming is located below the maximum winter MLD $(\sim 220 \mathrm{~m})$ due to damping of the temperature anomalies within the mixed layer by the surface heat flux. Maximum SST anomalies are found in February and March in accordance with the maximum anomalous OHFC forcing as well as the deepest mixed layer which entrains warmer anomalies from the thermocline. The mixed layer is deeper in the perturbation experiment (thick solid line in Fig. 2c) than the control integration (dashed line in the same panel) especially in winter by up to $100 \mathrm{~m}$. Deepening of the winter mixed layer is primarily due to a weakening of the stratification in response to the specified anomalous OHFC between 100 and $200 \mathrm{~m}$ where the top of the thermocline is located in the control integration.

Net surface heat flux anomalies are from the ocean to atmosphere year-round, with maximum values in JanuaryMarch (Fig. 2b). The net surface heat flux feedback in December-March ranges from 26 to $33 \mathrm{~W} \mathrm{~m}^{-2 \circ} \mathrm{C}^{-1}$, somewhat smaller than the corresponding values estimated from the observations $\left(40-50 \mathrm{~W} \mathrm{~m}^{-2 \circ} \mathrm{C}^{-1}\right.$ ) (Frankignoul and Kestenare 2002; Park et al. 2005) and the CCSM2 (39 $\mathrm{W} \mathrm{m}^{-2 \circ} \mathrm{C}^{-1}$ for the December-March average) (Kwon and Deser 2007). The annual cycle of the atmospheric diabatic heating response closely follows that of the net surface heat flux (Fig. 2a). The significant responses reach up to $\sim 400 \mathrm{hPa}$ from September to March. Diabatic heating responses near the surface below $\sim 900 \mathrm{hPa}$ are dominated by the vertical diffusion of sensible surface heat flux anomalies, while condensational heating anomalies are primarily responsible for the responses above $\sim 900 \mathrm{hPa}$.

Hereafter, we focus on the January-March (winter) average response when the ocean-to-atmosphere heat flux and SST anomalies are largest. The individual monthly responses during winter are given at http://www.cgd.ucar. edu/cas/cdeser/CMLM_supfig.html. A cross-section of the winter response along $40^{\circ} \mathrm{N}$ exhibits maximum MLD,

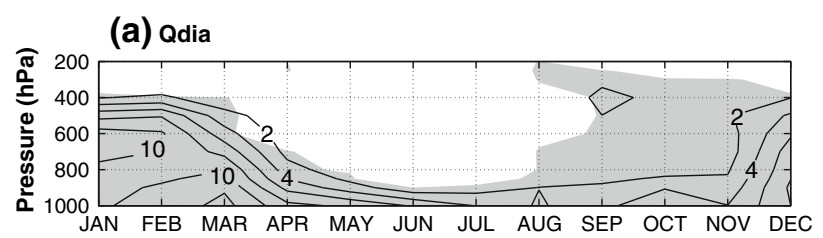

(b) Qnet

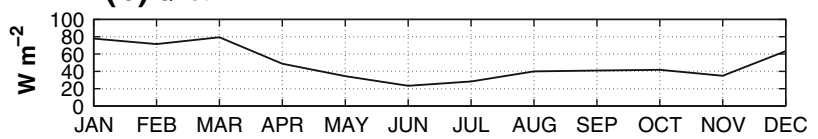

(c) T \& MLD

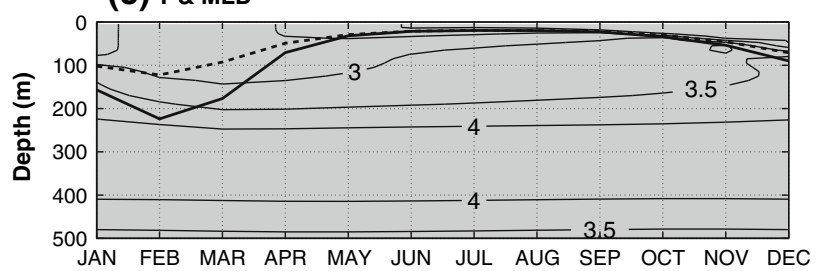

Fig. 2 Annual cycle of CMLM-E responses averaged over the Kuroshio Extension $\left(35^{\circ}-45^{\circ} \mathrm{N}, 140^{\circ} \mathrm{E}-180^{\circ}\right)$. a Diabatic heating. Contour interval is $2 \times 10^{-6} \mathrm{~K} \mathrm{~s}^{-1}$. Zero contour is suppressed. Shading indicates significance at $95 \%$ level. b Net surface heat flux. Positive is from ocean to atmosphere. Note that the values for all 12 months are significant at $95 \%$ level. c Ocean temperature. Contour interval is $0.5^{\circ} \mathrm{C}$. Shading covers the whole section because all values are significant at $95 \%$ level. Dashed thick contour is the MLD from the control integration and the solid thick contour is the MLD from the perturbation experiment. MLD anomalies for all the months except July are significant at $95 \%$ level 
(a) Qdia

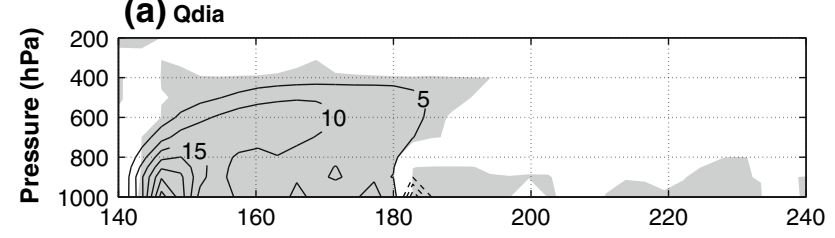

(b) Qnet

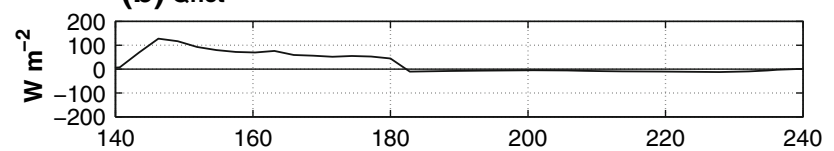

(c) T \& MLD

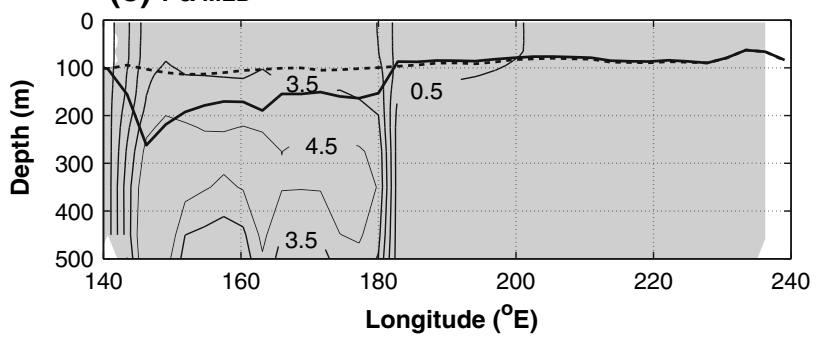

Fig. 3 Same as Fig. 2 but for winter (JFM) CMLM-E responses along a zonal section averaged over $35^{\circ}-45^{\circ} \mathrm{N}$. The contour interval is $5 \times 10^{-6} \mathrm{~K} \mathrm{~s}^{-1}$ in (a) and $1^{\circ} \mathrm{C}$ starting from $0.5^{\circ} \mathrm{C}$ in (c). Dashed contours in (a) indicate the negative anomalies. The net surface heat flux responses in (b) are significant at 95\% level except for the longitude band $195^{\circ}-205^{\circ} \mathrm{E}$, and the MLD responses in (c) are significant at $95 \%$ level except east of $215^{\circ} \mathrm{E}$

surface heat flux, and diabatic heating anomalies near the western end of the section (Fig. 3), collocated with the maximum specified OHFC (Fig. 1). The cross-section exhibits a marked contrast between the directly forced region to the west of the dateline and the downstream region to the east of the dateline where the surface heat flux response is weak and negative, i.e. from atmosphere to ocean. The anomalous heat is transported from the forcing region by the mean westerlies and deposited into the ocean via surface heat flux anomalies to cause a warming downstream. In contrast to the subsurface temperature anomaly maximum in the directly forced region west of the dateline, positive ocean temperature anomalies east of the dateline are concentrated within the mixed layer, although vertical diffusion extends them downward. Similarly, the diabatic heating response exhibits a maximum in the middle troposphere near the forcing region, while to the east of the dateline the negative anomalies are confined near the surface and are due to vertical diffusion associated with anomalous sensible surface heat flux from atmosphere to ocean.

The spatial pattern of the winter SST response in the forcing region directly reflects that of the OHFC forcing (Fig. 4a). However, the amplitude of the SST response is about four times larger than the root-mean-square of the 10-year low-pass filtered SST in the same region
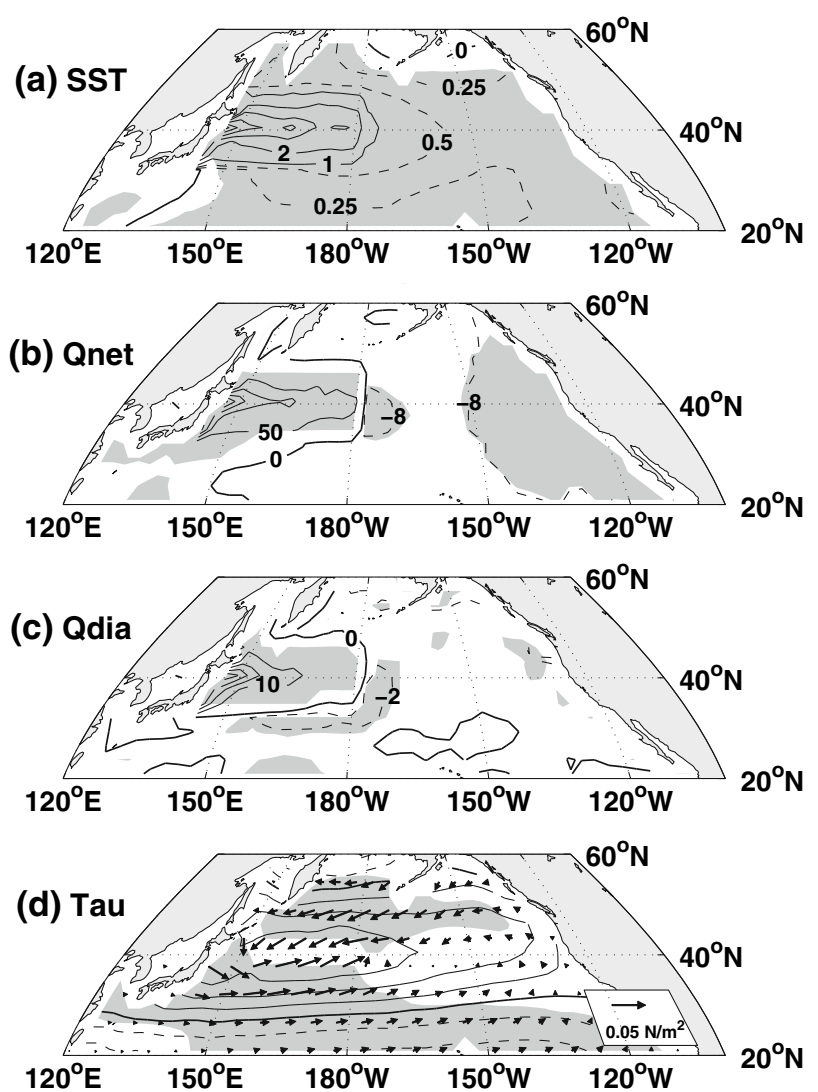

Fig. 4 Winter (JFM) CMLM-E responses. a SST. Contour interval is $1^{\circ} \mathrm{C}$, with the $0.25^{\circ} \mathrm{C}$ and $0.5^{\circ} \mathrm{C}$ contours indicated by the dashed lines. Shading indicates significance at $95 \%$ level. b Net surface heat flux. Positive values denote a flux from ocean to atmosphere. Contour interval is $50 \mathrm{~W} \mathrm{~m}^{-2}$ for values greater than or equal to zero (solid contours); dashed contours show the $-8 \mathrm{~W} \mathrm{~m}^{-2}$ values. c $850 \mathrm{hPa}$ diabatic heating. Contour interval is $10 \times 10^{-6} \mathrm{~K} \mathrm{~s}^{-1}$. Dashed contours indicate $-2 \times 10^{-6} \mathrm{~K} \mathrm{~s}^{-1}$. d Surface wind stress (vectors) superimposed upon zonal wind stress from the control integration (CMLM-C; contours). Contour interval is $0.05 \mathrm{~N} \mathrm{~m}^{-2}$. Positive and zero (negative) values are plotted with solid (dashed) contours

$\left(35^{\circ}-45^{\circ} \mathrm{N}, 140^{\circ} \mathrm{E}-180^{\circ}\right)$ from the CCSM2, i.e. $3.0^{\circ} \mathrm{C}$ for the CMLM-E compared to $0.7^{\circ} \mathrm{C}$ for the CCSM2. Lack of dynamical damping due to neglected lateral processes in the MLM (i.e. horizontal advection and diffusion) appears to be responsible for the discrepancy.

Weak $\left(<1^{\circ} \mathrm{C}\right)$ positive SST anomalies (indicated by the dashed contours) outside of the forcing region are driven by atmosphere-to-ocean (i.e. negative) surface heat flux anomalies (Fig. 4a, b). The spatial pattern of the surface heat flux and the $850 \mathrm{hPa}$ diabatic heating anomalies exhibit a clear distinction between the directly forced region in the Kuroshio Extension and the opposite-signed anomalies outside of this region. The spatial pattern of positive diabatic heating anomalies does not change much up to $400 \mathrm{hPa}$ except for a slight eastward displacement with height (not shown). The surface wind stress response exhibits an anomalous cyclonic circulation basin-wide in 
extent and centered over the maximum positive SST anomalies along the Kuroshio Extension (Fig. 4d). The comparison with the climatological mean zonal wind stress (contours in the Fig. 4d) suggests that the anomalies represent a southward shift of the surface westerly jet.

The CMLM-E sea-level pressure (SLP) and $250 \mathrm{hPa}$ geopotential height (Z250) responses for January-March in the Northern Hemisphere north of $20^{\circ} \mathrm{N}$ are presented in the first column of Fig. 5 along with the SST and net surface heat flux responses. The basin-wide negative SLP anomalies in the North Pacific correspond to the cyclonic wind stress anomalies in Fig. 4d. The maximum low pressure anomaly is located slightly downstream of the maximum SST anomaly with amplitude $\sim 2 \mathrm{hPa}$ in response to a $\sim 3^{\circ} \mathrm{C}$ SST warming averaged over the forcing region. A significant high pressure response is found over the North Atlantic and downstream over western Siberia, with maximum amplitude $\sim 2 \mathrm{hPa}$. This atmospheric circulation response over the North Atlantic locally drives positive anomalies in the atmosphere-toocean heat flux which in turn leads to positive SST anomalies of modest amplitude. The Z250 responses exhibit generally positive anomalies over high latitudes, with a maximum over the North Atlantic $(\sim 40 \mathrm{~m})$, and negative anomalies to the south. The zonally asymmetric component of the Z250 response exhibits a circumglobal zonal wavenumber five pattern along the midlatitude jet (Branstator 2002). The vertical structure of the circulation response is baroclinic over the North Pacific and equivalent barotropic over the North Atlantic and western Siberia. The North Atlantic component of the response is robust and stable throughout the winter months of November-March, while the negative SLP anomaly response in the North Pacific begins to emerge in December and exhibits full amplitude from January through March, following the development of the SST anomalies (Fig. 6). The Z250 anomalies in the North Pacific remain positive throughout the winter although their location and magnitude vary somewhat from month to month (not shown).

\subsection{CMLM-G experiment}

The CMLM-G exhibits very similar winter SST and surface heat flux responses to those of CMLM-E (Fig. 5). However, the SLP and the Z250 anomalies from the two experiments bear some interesting differences. Over the North Pacific, the negative (positive) SLP (Z250) response in CMLM-G is approximately half (double) the magnitude of that in CMLM-E. In addition, the response over the North Atlantic is diminished considerably and shifted
Fig. 5 Winter (JFM) responses. (Top row) $250 \mathrm{hPa}$ geopotential height, (second row) sea-level pressure, (third row) net surface heat flux, and (bottom row) SST from (first column) CMLM-E, (second column) CMLM-G, (third column) CMLM-G minus CMLM-E, and (fourth column) AGCM-E. Positive (negative) responses are plotted with solid (dashed) contours. Zero contours are suppressed. Contour intervals are $10 \mathrm{~m}$, $1 \mathrm{hPa}, 50 \mathrm{~W} \mathrm{~m}^{-2}$, and $1^{\circ} \mathrm{C}$, respectively. Note that the additional thin solid and dashed contours for the net surface heat flux and SST indicate $\pm 10 \mathrm{~W} \mathrm{~m}^{-2}$ and $\pm 0.2^{\circ} \mathrm{C}$, respectively. Shading indicates significance at $95 \%$ level. The projection is for the northern hemisphere poleward of $20^{\circ} \mathrm{N}$ with the latitude circles at 40,60 and $80^{\circ} \mathrm{N}$

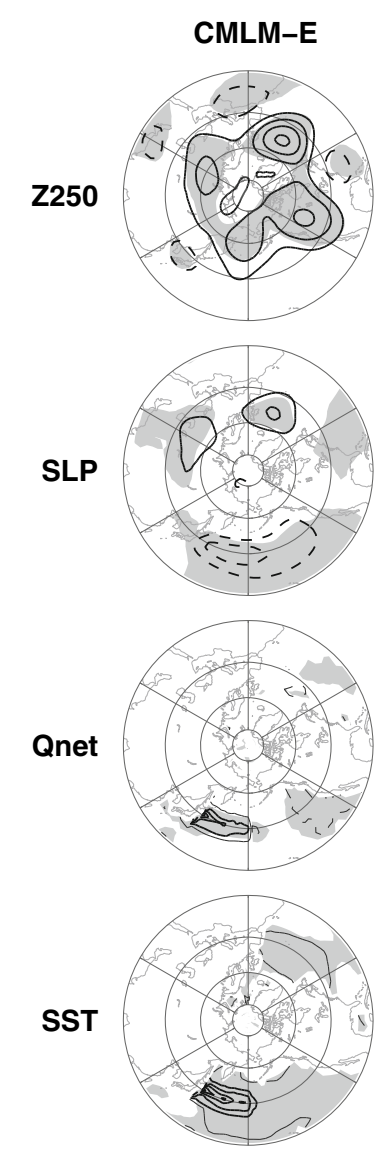

\section{CMLM-G}
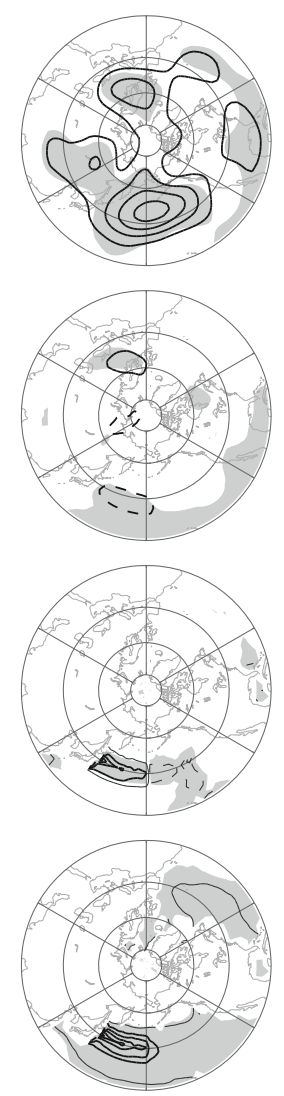

CMLM-G minus CMLM-E
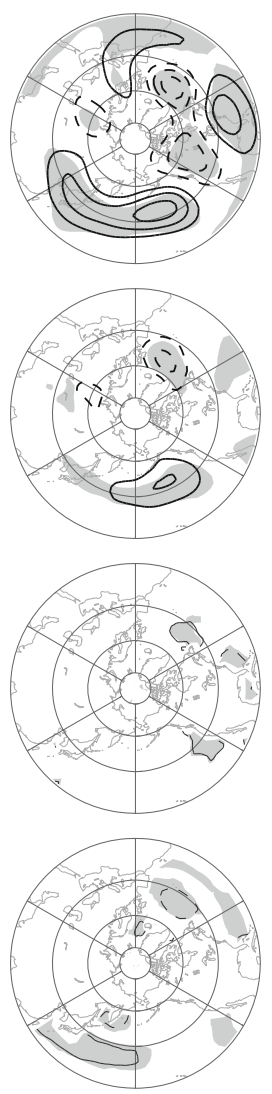
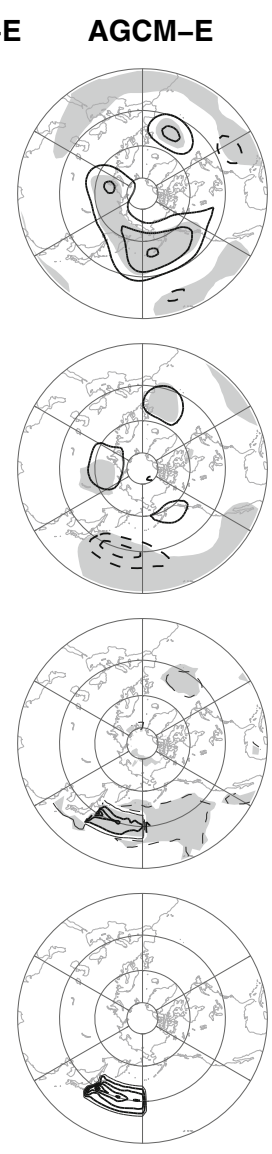
Fig. 6 Monthly equilibrium responses of (top) CMLM-E sea-level pressure (middle) AGCM-E sea-level pressure, and (bottom) AGCM-E SST. Positive (negative) responses are plotted with solid (dashed) contours. Zero contours are suppressed. Contour intervals are $1 \mathrm{hPa}$. Shading indicates significance at $95 \%$ level
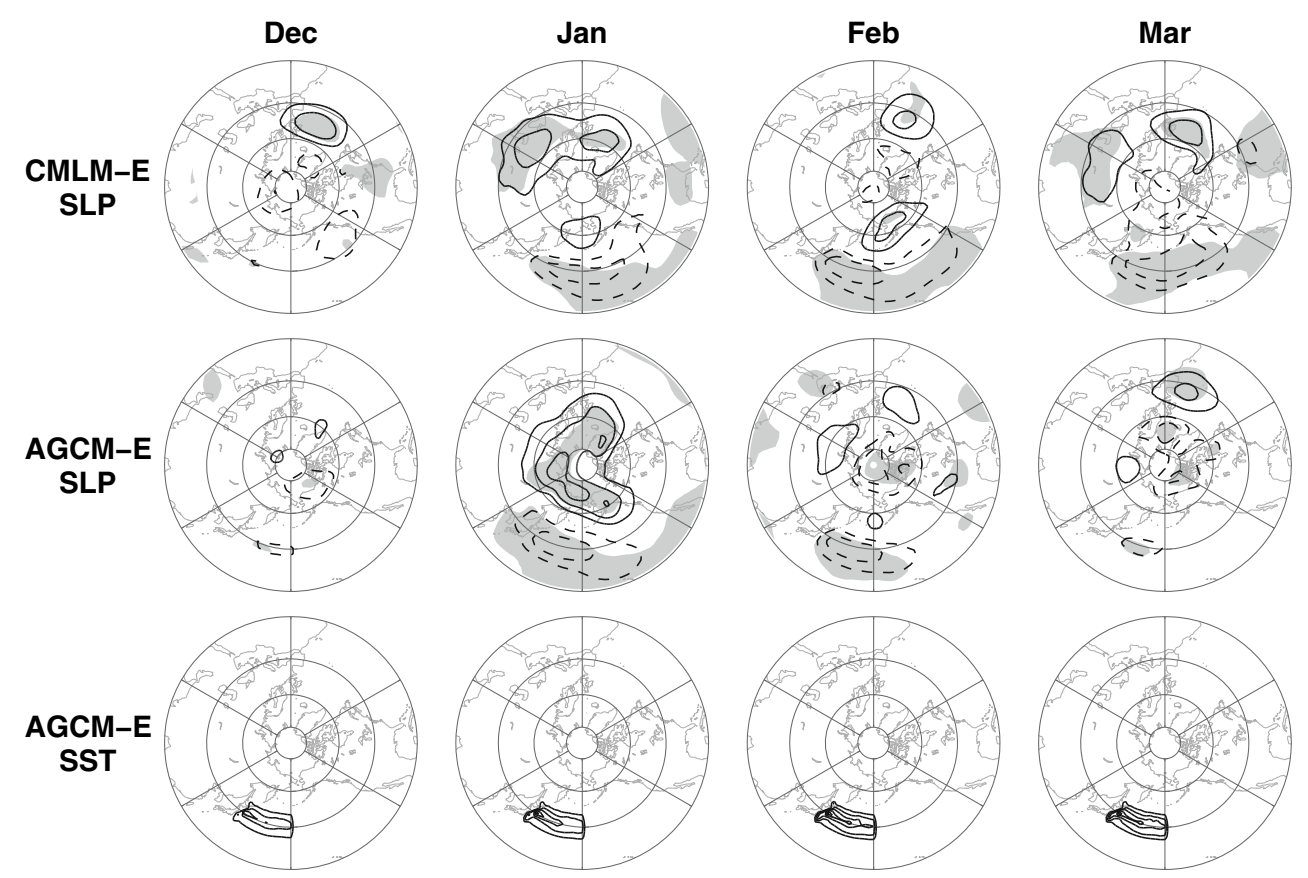

(a) CMLM-E

eastward. To highlight the differences between the two experiments, the CMLM-G responses minus the corresponding CMLM-E responses are presented in the third column of Fig. 5. The differences in the atmospheric circulation responses consist of an equivalent barotropic ridge over the North Pacific and a more spatially confined equivalent barotropic low over the North Atlantic, with maximum anomalies $\sim 2 \mathrm{hPa}$ in SLP and $\sim 30 \mathrm{~m}$ in Z250. The Z250 difference pattern resembles the Pacific-North American (PNA) teleconnection pattern (Wallace and Grutzler 1981), although the downstream center over the subpolar North Atlantic is stronger than typical. The SST differences exhibit positive anomalies $\sim 0.2^{\circ} \mathrm{C}$ directly south of the forcing region and a smaller patch of negative anomalies to the north. These weak SST anomalies appear to be driven by anomalous atmosphere-to-ocean heat flux associated with the positive SLP anomaly center. Similar atmospheric circulation-induced anomalous heat fluxes also appear to drive the SST differences in the North Atlantic.

What drives the differences in the circulation responses in CMLM-E and CMLM-G, in particular the equivalent barotropic high over the North Pacific and associated PNA pattern? We argue that the presence of an interactive ocean mixed layer in the tropics in CMLM-G leads to a tropical rainfall response which in turn provides an additional forcing mechanism for the extratropical atmospheric circulation. Figure 7 shows that CMLM-E does not exhibit any significant tropical rainfall response while CMLM-G shows negative (positive) rainfall anomalies along the equator $\left(\sim 5^{\circ} \mathrm{N}\right)$ in the central and western tropical Pacific,

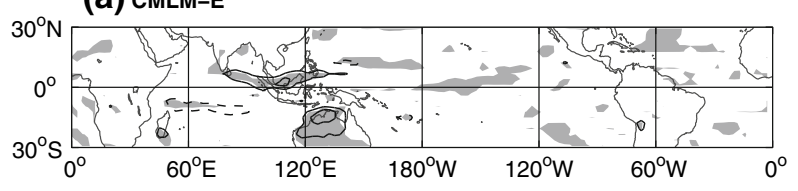

(b) CMLM-G

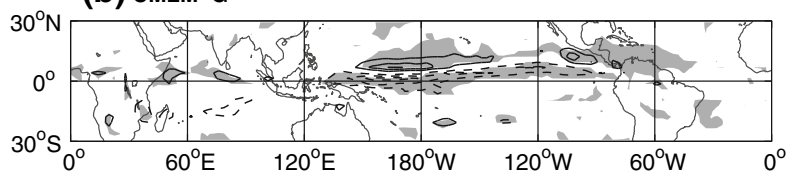

(c) CMLM-G minus CMLM-E

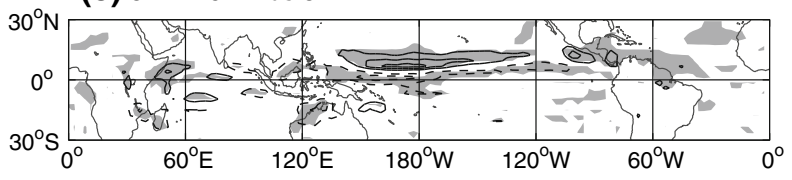

Fig. 7 DJF responses of precipitation in the tropics for (a) CMLM-E (b) CMLM-G, and (c) CMLM-G minus CMLM-E. Positive (negative) responses are plotted with solid (dashed) contours. Zero contours are suppressed. Contour intervals are $0.5 \mathrm{~mm} \mathrm{day}^{-1}$. Gray shading indicates significance at $95 \%$ level

with maximum amplitudes $\sim \pm 1 \mathrm{~mm} \mathrm{day}^{-1}$, which corresponds to about $40 \%$ of the root-mean-square of the December-February average tropical precipitation in CCSM2. The CMLM-G rainfall anomalies are accompanied by weak but significant tropical SST anomalies $\left(\sim \pm 0.2^{\circ} \mathrm{C}\right.$; not shown). Note that the tropical rainfall anomalies are averaged over December-February to account for the approximately 1-month delay between tropical forcing and extra-tropical atmospheric circulation response (Trenberth et al. 1998; Alexander et al. 2002). 
The anomalous precipitation pattern in CMLM-G, which implies a northward migration of the Inter-Tropical Convergence Zone (ITCZ), resembles that of ENSO in its negative phase (Deser et al. 2006).

\subsection{AGCM-E}

Next, we compare the CMLM approach with the traditional specified-SST approach for assessing the atmospheric response to anomalous SSTs. In AGCM-E, SST anomalies identical to those in CMLM-E are specified over the forcing region $\left(35^{\circ}-45^{\circ} \mathrm{N}, 140^{\circ} \mathrm{E}-180^{\circ}\right.$; Fig. 5). The general features of the circulation responses in the two experiments are similar, with a baroclinic vertical structure over the North Pacific and an equivalent barotropic structure over the North Atlantic and Siberia. However, the North Pacific SLP response is more spatially confined over the western half of the basin in AGCM-E compared to CMLM-E. Thus, the SLP anomalies averaged over the North Pacific basin $\left(20^{\circ}-60^{\circ} \mathrm{N}, 140^{\circ} \mathrm{E}-120^{\circ} \mathrm{W}\right)$ are $-0.83 \mathrm{hPa}$ for CMLM-E compared to only $-0.26 \mathrm{hPa}$ for AGCM-E. The weaker January-March average response in AGCM-E is due to the rapid decay of the response in late winter, a feature not seen in CMLM-E (Fig. 6). By March, the amplitude of the SLP anomalies averaged over the North Pacific basin $\left(20^{\circ}-60^{\circ} \mathrm{N}, 140^{\circ} \mathrm{E}-120^{\circ} \mathrm{W}\right)$ in AGCM$\mathrm{E}$ is $<10 \%$ of that in CMLM-E and insignificant except for a small region east of Japan (Fig. 6). In addition to differences in the SLP responses, the Z250 response over the North Pacific (Atlantic) is larger (smaller) in AGCM-E compared to CMLM-E. Unlike the SLP response, the Z250 response in AGCM-E does not exhibit a weakening in late winter over the North Pacific (not shown).

We propose that most of the differences between the AGCM-E and CMLM-E responses can be attributed to the role of the ocean mixed layer outside of the forcing region. In particular, AGCM-E exhibits a larger atmosphere-toocean heat flux to the east of the dateline compared to CMLM-E (and CMLM-G) along $40^{\circ} \mathrm{N}$ (Fig. 8), because the fixed SST in AGCM-E acts as an infinite heat reservoir (Barsugli and Battisti 1998). The maximum atmosphere-toocean heat flux anomaly is $-37 \mathrm{~W} \mathrm{~m}^{-2}$ in AGCM-E, while it is $-12 \mathrm{~W} \mathrm{~m}^{-2}$ and $-10 \mathrm{~W} \mathrm{~m}^{-2}$ in CMLM-E and CMLM-G, respectively. As a result, the associated negative diabatic heating anomalies east of the dateline in AGCM-E exhibit greater amplitude than either CMLM experiment. We conjecture that this anomalous diabatic cooling to the east of the dateline drives a local positive SLP response that acts to partially offset the negative SLP response due to the positive SST/diabatic heating anomalies in the Kuroshio Extension. Consequently, the atmospheric temperature and low-level geopotential height responses are more confined to the western portion of the basin in AGCM-E than CMLM-E (Fig. 8). In AGCM-E, the growth of the SST anomalies in the forcing region from December through March leads to a corresponding growth in the negative diabatic heating response to the east which in turn explains the progressive weakening of the negative SLP response as documented in Fig. 6. It is worth noting that AGCM-E exhibits insignificant tropical precipitation responses (not shown).

\subsection{Wind stress curl response}

Part of the motivation for this study is to better understand the atmospheric circulation response to SST anomalies in the Kuroshio Extension region due to its crucial role in sustaining the decadal coupled atmosphere-ocean mode in CCSM2 (Kwon and Deser 2007). Of particular importance is the wind stress curl component of the response which drives geostrophic ocean circulation changes that in turn alter SSTs in the Kuroshio Extension region. The JFM wind stress curl responses in CMLM-E, CMLM-G and AGCM-E are shown in Fig. 9; their annual mean counterparts are very similar (not shown). The patterns of wind stress curl response are similar in all three experiments, with comparable amplitudes for CMLM-E and AGCM-E and weaker magnitudes for CMLM-G, in keeping with the SLP responses (recall Fig. 5). One may infer from the difference between the CMLM-G and CMLM-E wind stress curl responses that the tropically forced teleconnection partially opposes the direct response (Figs. 9d). Thus, the thermally coupled tropics act as a weak damping to the North Pacific decadal oscillation in CCSM2. The implication of these response patterns for the decadal variability in CCSM2 will be discussed further in Sect. 4.5.

\section{Discussion}

\subsection{Role of the tropical ocean mixed layer}

Previous modeling studies have repeatedly shown that tropics are sensitive to specified extratropical thermal anomalies either introduced directly as temperature or heat flux anomalies or indirectly as sea-ice or fresh water anomalies (Chiang and Bitz 2005; Broccoli et al. 2006; Kang et al. 2008; Wu et al. 2008; Chiang et al. 2008; Okumura et al. 2009). Our winter atmospheric circulation response to anomalous OHFC in the Kuroshio Extension is substantially modified by the presence of a thermodynamically active ocean mixed layer in the tropics. When the tropical ocean mixed layer is active, the Pacific ITCZ shifts northward toward the warmed hemisphere, consistent with previous studies (e.g. Chiang and Bitz 2005; Kang et al. 2008). The ITCZ displacement induces an extratropical PNA-like 
CMLM-E

$\mathbf{Z}$
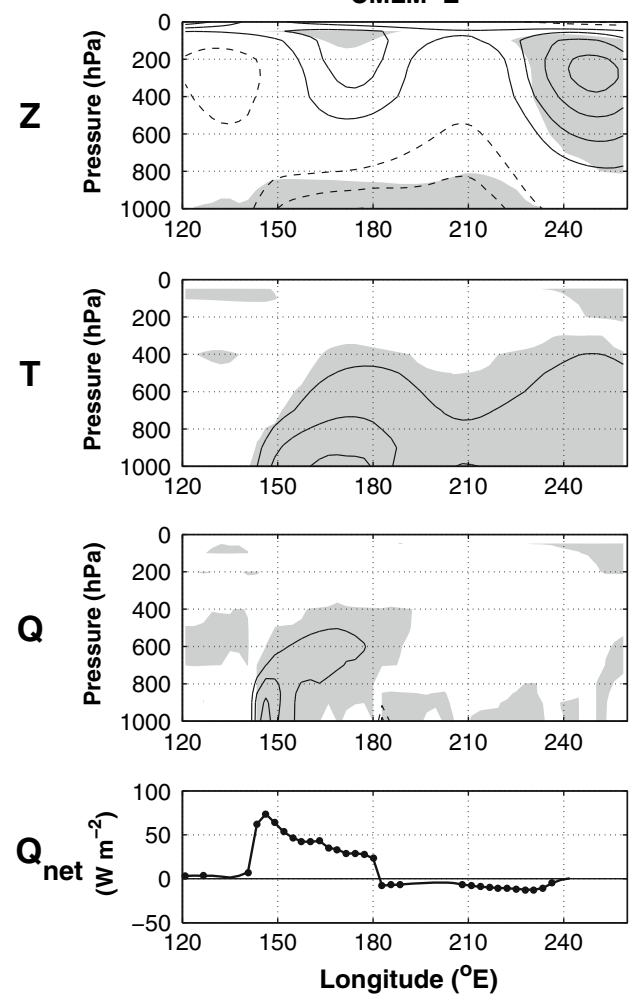

CMLM-G
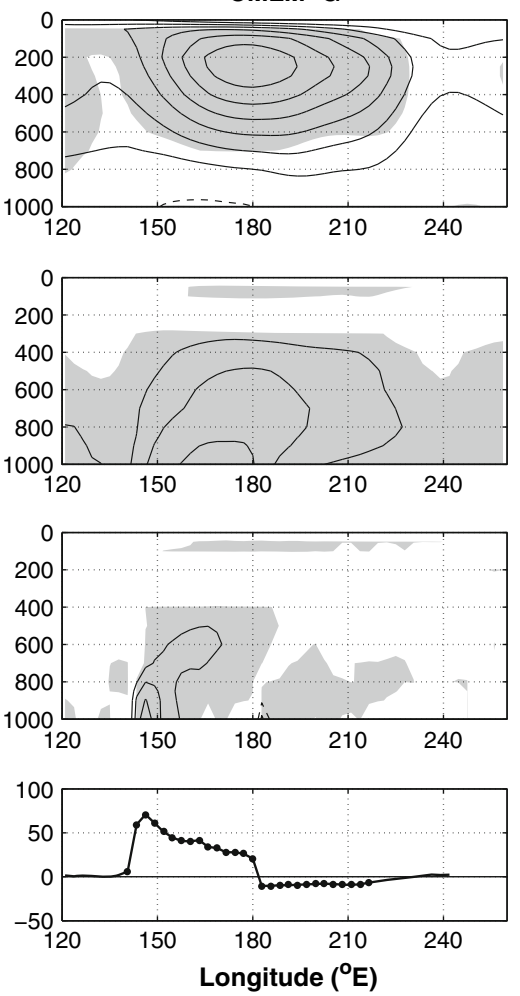

AGCM-E
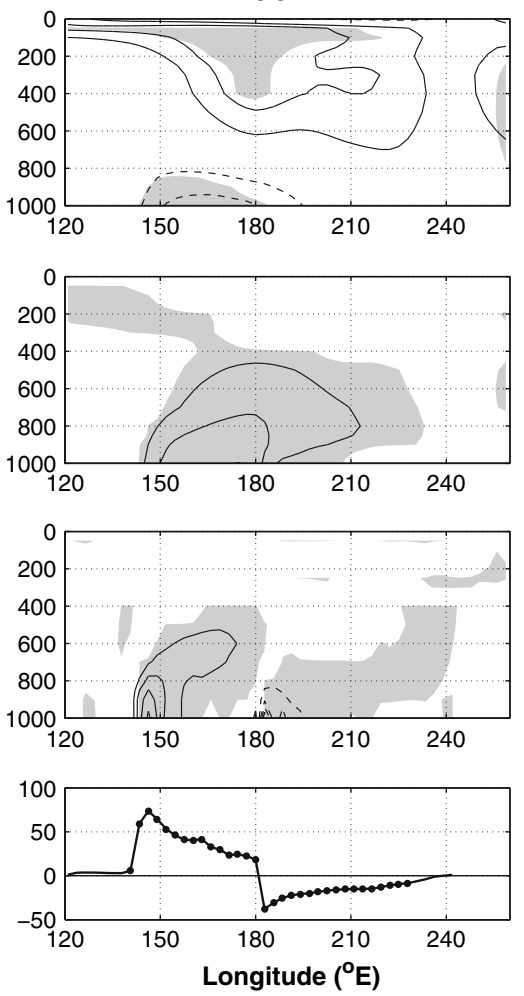

Fig. 8 JFM equilibrium responses along a zonal section averaged for $30^{\circ}-50^{\circ} \mathrm{N}$ of (top row) geopotential height (second row) atmospheric temperature (third row) diabatic heating, and (bottom row) net surface heat flux from (left) CMLM-E (center) CMLM-G, and (right) AGCM-E. (Top three rows) Positive (negative) responses are plotted

with solid (dashed) contours. Zero contours are suppressed. Contour intervals are $5 \mathrm{~m}, 0.5 \mathrm{~K}$, and $5 \times 10^{-6} \mathrm{~K} \mathrm{~s}^{-1}$, respectively. Shading indicates significance at $95 \%$ level. (Bottom row) Positive values indicate the anomalous net surface heat flux is from ocean to atmosphere. Dotted values are significant at the $95 \%$ confidence level

Fig. 9 JFM wind stress curl responses from (a) CMLM-E (b) CMLM-G (c) AGCM-E, and (d) CMLM-G minus CMLM-E. Contour intervals are $2 \times 10^{-8}$ $\mathrm{N} \mathrm{m}^{-3}$. Negative values are dashed and shading indicates significance at $95 \%$ level (a) CMLM-E

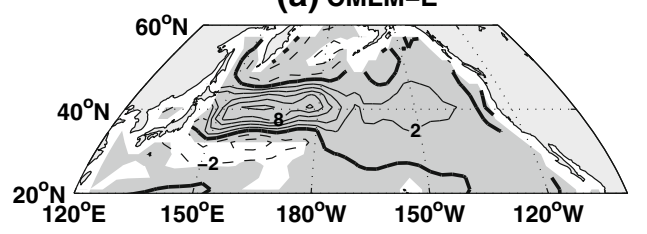

(c) AGCM-E

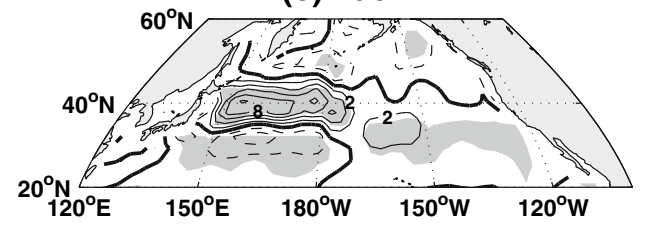

(b) CMLM-G

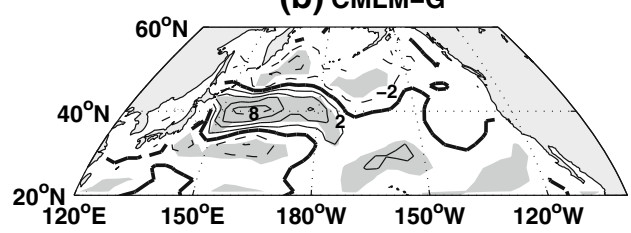

(d) CMLM-G minus CMLM-E

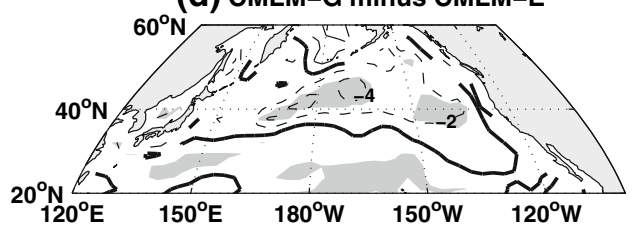

atmospheric response, with an equivalent barotropic ridge over the North Pacific that competes with the locally forced baroclinic response. The mechanism for the northward displacement of the Pacific ITCZ in our experiments with an active tropical ocean mixed layer requires further investigation. A possible explanation is the framework proposed by Kang et al. (2008) in which atmospheric meridional energy fluxes change in such a way as to partially compensate the implied oceanic fluxes associated with the imposed OHFC anomaly. In addition, the wind-
evaporation-SST feedback mechanism may also be important (Chiang and Bitz 2005). It remains to be seen whether the inclusion of a dynamically active tropical upper ocean produces a similar ITCZ response as our mixed layer tropical ocean.

\subsection{Role of the extratropical ocean mixed layer}

In late winter, the presence of an active ocean mixed layer in the extra-tropics leads to a stronger surface low response 
over the North Pacific compared to the case without an ocean mixed layer. We propose that this is due not to any influence from the tropics, but because the 'specified-SST' experiment (AGCM-E) lacks the so-called "reduced damping" effect due to thermal adjustment between the ocean and atmosphere (Barsugli and Battisti 1998). That is, excessive heat loss from the atmosphere to the ocean in the 'specified SST' experiment acts as a negative feedback to the direct response not just to the east of the dateline but also within the forcing region. This result suggests a potential deficiency inherent in specified-SST experiments. We note that in the case of perpetual experiments for a given month (e.g. Peng et al. 1997), the negative feedback could have ample time to grow and completely offset the primary response.

Liu and Wu (2004) also considered the lack of "reduced damping" when comparing their specified SST experiment with their fully coupled model and specified surface heat flux experiments. However, in contrast to our results, their specified SST and coupled model experiments yielded similar atmospheric circulation responses. We note, however, that their findings are based on ensemble integrations for early winter (November-December) with constant amplitude SST forcing, in contrast to our results for late winter and amplifying SST anomalies.

\subsection{Comparison with previous studies}

As discussed in the introduction, Yulaeva et al. (2001) conducted an experiment very similar to CMLM-G. However, unlike the baroclinic (low-level trough, upperlevel ridge) response found in CMLM-G, Yulaeva et al. (2001) obtained an equivalent barotropic response consisting of a trough over and downstream of the forcing region directly east of Japan and a ridge over Alaska and western Canada. The possible role of tropical precipitation changes in modifying the atmospheric circulation response over the north Pacific was not explored in Yulaeva et al. (2001), although their experimental design included an interactive ocean mixed layer in the tropics. This aspect, coupled with the relatively small sample size (10 ensemble members compared to $\sim 100$ here) and different definition of winter (December-February compared to JanuaryMarch here), makes it difficult to ascertain the causes for the differing responses in Yulaeva et al. (2001) and CMLM-G. In terms of wind stress curl, the North Pacific response in Yulaeva et al. (2001) resembles that in CMLMG (and CMLM-E), with positive anomalies in the latitude band $30^{\circ}-50^{\circ} \mathrm{N}$ which in turn provides a negative feedback to the prescribed OHFC. It provides a negative feedback because the positive anomalous wind stress curl response implies the southward migration of the zero wind stress curl line accompanied by the southward migration of the
Kuroshio Extension front 3-5 years later, which causes the negative OHFC and cold SST anomalies in the Kuroshio Extension. Thus, their wind stress curl response would support the existence of a coupled atmosphere-ocean decadal oscillation as in our experiments, despite differences in the vertical structures of the atmospheric circulation response.

The fully coupled model experiments by Liu and $\mathrm{Wu}$ (2004) and Liu et al. (2007) may also have involved tropical precipitation anomalies but these were not explicitly examined. Liu et al. (2007) compared the responses for November-January and February-April and found an equivalent barotropic ridge response in early winter and a baroclinic (low-level trough and upper-level ridge) response in late winter. The monthly evolution of the atmospheric response in our coupled model experiments (CMLM-E and CMLM-G) is largely consistent with that of Liu et al. (2007) although the equivalent barotropic ridge response is confined to November with a gradual strengthening of the baroclinic response from December to March.

\subsection{Comparison with the CCSM2 responses}

Kwon and Deser (2007) empirically diagnosed the wind stress curl response to anomalous geostrophic OHFC along the Kuroshio Extension in CCSM2 by linearly regressing the anomalous wind stress curl field lagged by 1-year upon the Kuroshio Extension SST anomaly index. The 1-year lag was used to distinguish the atmospheric response to SST from the atmospheric forcing of SST which is otherwise confounded in the simultaneous regression. This approach relies on the fact that the wind stress curl anomalies contain practically no memory from 1 year to the next, while SST anomalies exhibit high persistence from one winter to the next. The CCSM2 JFM SLP and $\mathrm{Z} 250$ responses obtained using this empirical technique are shown in Fig. 10, scaled by the ratio of the standard deviation of the CCSM2 and CMLM-E SST anomalies averaged over the Kuroshio Extension $\left(0.7^{\circ} \mathrm{C} / 3.0^{\circ} \mathrm{C}\right.$; recall Sect. 3.1). Note that the ENSO influence is removed based on subtracting linear regressions of SLP and Z250 on the first and second principal component time series of the tropical SST $\left(10^{\circ} \mathrm{S}-10^{\circ} \mathrm{N}, 130^{\circ} \mathrm{E}-90^{\circ} \mathrm{W}\right)$ to obtain the direct responses most relevant to the CMLM-E response. The pattern and amplitude of the SLP response in CCSM2 is similar to that in CMLM-E, with negative values over the North Pacific centered along $40^{\circ} \mathrm{N}$ and positive values north of $60^{\circ} \mathrm{N}$. The $\mathrm{Z} 250$ response pattern in CCSM2 also bears some similarity with that in CMLM-E, with positive values near the Arctic north of $50^{\circ} \mathrm{N}$. However, the negative values over the North Pacific centered along $40^{\circ} \mathrm{N}$ are much stronger and broader. Thus, the extra-tropical 
(a) Z250

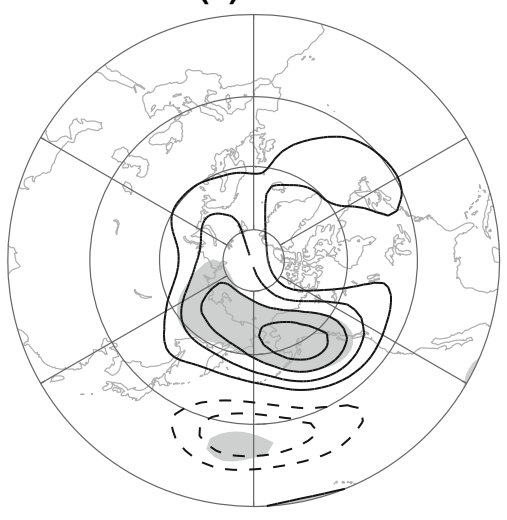

(b) SLP

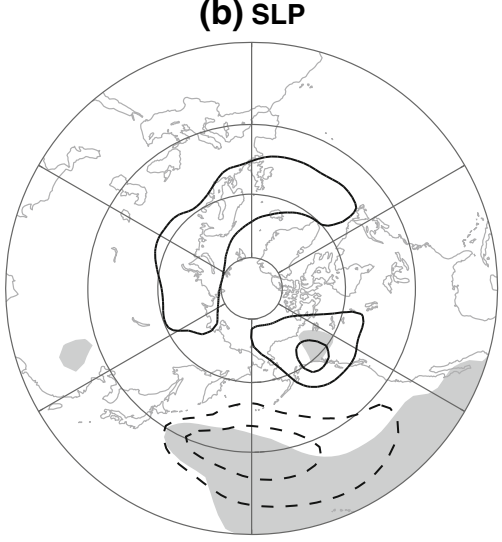

Fig. 10 JFM CCSM2 responses to the Kuroshio Extension SST anomalies for (a) $250 \mathrm{hPa}$ geopotential height, and (b) sea-level pressure. The responses are calculated after the ENSO influence is removed based on the linear regression and scaled by the ratio between the standard deviation of CCSM2 and CMLM-E SST anomalies averaged in the Kuroshio Extension. Positive (negative) responses are plotted with solid (dashed) contours. Zero contours are suppressed. Contour intervals are $10 \mathrm{~m}$ and $1 \mathrm{hPa}$, respectively. Shading indicates significance at $95 \%$ level

response is equivalent barotropic, even over the North Pacific, unlike that in CMLM-E, CMLM-G or AGCM-E.

Despite the fact that the North Pacific SLP responses are twice as large in CMLM-E and CCSM2 as in CMLM-G, the North Pacific wind stress curl response is only 1.2 times as large (Fig. 11). This is due to the fact that the anomalous wind stress curl is proportional to the amplitude of the anomalous SLP and inversely proportional to the spatial scale of the anomalous SLP via the Laplacian operator. The larger spatial scale of the SLP response in CMLM-G compared to CMLM-E and CCSM2 partially offsets the difference in amplitude, yielding a more comparable wind stress curl response. This mismatch occurs because the remote component of the North Pacific SLP response forced by tropical precipitation anomalies has a broader spatial scale than the local component of the SLP response forced directly by the Kuroshio Extension SST anomalies. Thus, due to their larger spatial scale, tropical atmospheric teleconnections may have a smaller influence on wind stress curl than on SLP over the North Pacific, a result that has implications for decadal variability of the Pacific coupled atmosphere-ocean system.

\subsection{Linear Rossby wave model}

Kwon and Deser (2007) suggested that North Pacific quasidecadal (15-20 year) variability in CCSM2 results from two-way ocean-atmosphere coupling involving the dynamical adjustment of the ocean gyre circulation via first-mode baroclinic Rossby waves to basin-scale wind stress curl anomalies $\sim 3-5$ years earlier and a response of the large-scale wind stress curl field to SST anomalies in the Kuroshio Extension induced by the ocean gyre circulation changes. Their argument was based on calculations with a linear Rossby wave model driven by the CCSM2 wind stress curl anomaly pattern that precedes Kuroshio Extension SST anomalies by 3-5 years (Fig. 12a). The temporal evolution of the wind stress curl anomaly pattern contains a weak quasi-decadal spectral peak which, although not statistically significant, is crucial for sustaining a robust quasi-decadal spectral peak in SST along the Kuroshio Extension. Kwon and Deser (2007) argued that the annual mean wind stress curl response pattern to SST anomalies in the Kuroshio Extension (Fig. 12b), diagnosed empirically from CCSM2 using lag-regression analysis as described in the previous section, was sufficiently similar to that of the forcing pattern (but of opposite sign and weaker amplitude) so as to support the existence of the ocean-atmosphere coupled mode.

However, closer inspection reveals that the wind stress curl response patterns (Fig. 12b, c) exhibit largest amplitudes over the western half of the North Pacific, unlike the forcing pattern which is strongest in the central basin. This may diminish the amplitude and period of the oscillation due to the shorter fetch for the westward-propagating Rossby waves. Therefore, we assess to what extent the quasi-decadal variability can be recovered from the linear first-mode baroclinic Rossby wave model of Kwon and Deser (2007) when explicitly using the annual-mean wind stress curl response patterns identified empirically from CCSM2 and obtained directly from the CMLM-E experiment. Note both response patterns in Fig. 12 have been scaled by the ratio of the standard deviations of the CCSM2 and CMLM-E SST anomalies averaged over the Kuroshio Extension for ease of comparison with the CCSM2 forcing pattern. The time series associated with the response pattern is obtained by projecting the pattern upon the CCSM2 wind stress curl anomaly in each month and year of the 650 -year simulation over the latitude band $30^{\circ}-50^{\circ} \mathrm{N}$. The response pattern and time series are then added to the CCSM2 wind stress curl forcing pattern whose time 


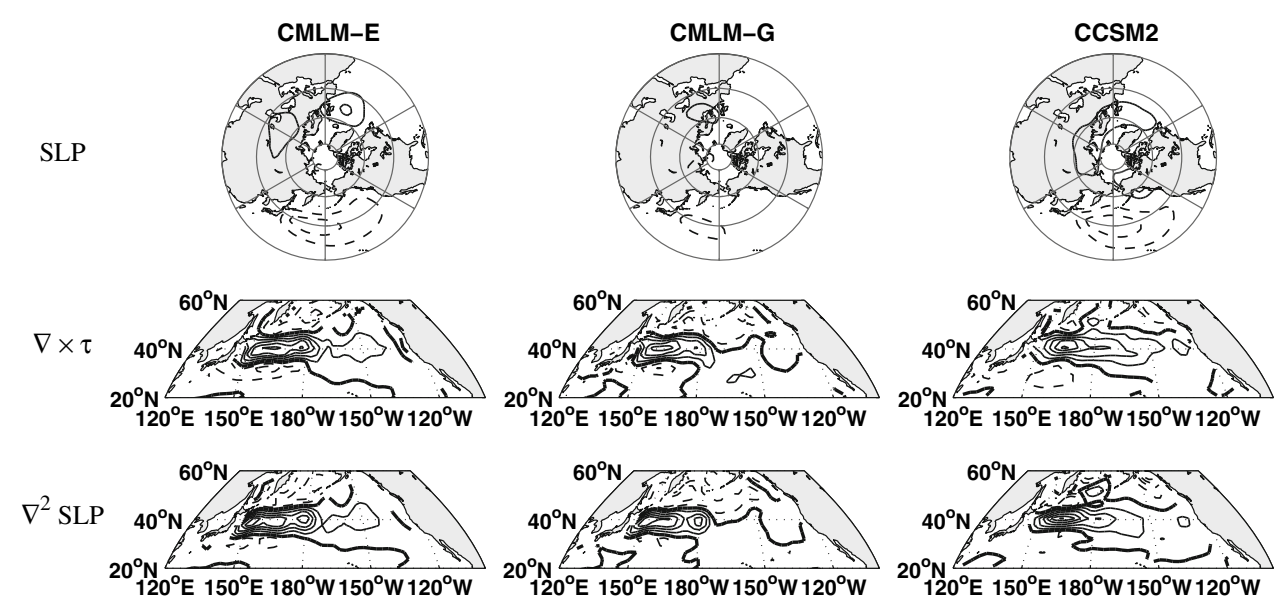

Fig. 11 JFM responses for (top row) sea-level pressure (middle row) wind stress curl, and (bottom row) Laplacian of sea-level pressure from (left column) CMLM-E (center column) CMLM-G, and (right column) CCSM2. The CCSM2 responses are calculated after the ENSO influence is removed based on the linear regression and scaled by the ratio between the standard deviation of CCSM2 and CMLM-E
SST anomalies averaged in the Kuroshio Extension. Positive (negative) responses are plotted with solid (dashed) contours. Zero contours are suppressed in the sea-level pressure plots. Contour intervals are $1 \mathrm{hPa}, 2 \times 10^{-8} \mathrm{~N} \mathrm{~m}^{-3}$, and $1.5 \times 10^{-12} \mathrm{hPa} \mathrm{m}^{-2}$, respectively

series has been artificially whitened so that it contains no spectral peaks. The amplitude of the whitened forcing is set to correspond to the minimum spectral power in the original forcing time series at periods longer than 10 years. It should be noted that the forcing pattern resembles the leading mode of atmospheric circulation variability over the North Pacific (see Kwon and Deser 2007).

The calculated sea surface height $(\mathrm{SSH})$ responses (equivalent to SST in the Rossby wave model) in the Kuroshio Extension reproduces the quasi-decadal spectral peak in CCSM2 SSH, albeit 20\% weaker (Fig. 13). The white-noise wind stress curl forcing produces a background red-noise response (gray line in Fig. 13b), while the wind stress curl response to SST anomalies in the Kuroshio Extension generates the additional quasi-decadal spectral peak. The multi-decadal ( $\sim 40$ years) peak is considerably damped in the Rossby wave model hindcast, suggesting that this peak is generated by processes other than firstmode baroclinic Rossby wave adjustment along the latitude band of the Kuroshio Extension, for example higher-mode Rossby waves or first-mode baroclinic Rossby wave adjustment at higher latitudes (Zhong and Liu 2009). The weaker amplitude of the quasi-decadal spectral peak is due to the presence of negative wind stress curl anomalies to the north and south of the Kuroshio Extension in the CCSM2 and CMLM-E response patterns: when these are artificially damped, the Rossby wave model hindcast produces a spectral peak that is comparable to that in CCSM2 SSH (not shown). Therefore, the wind stress response patterns, albeit weaker and centered farther west compared to the forcing pattern, do maintain a quasi-decadal coupled oscillation in the North Pacific. 

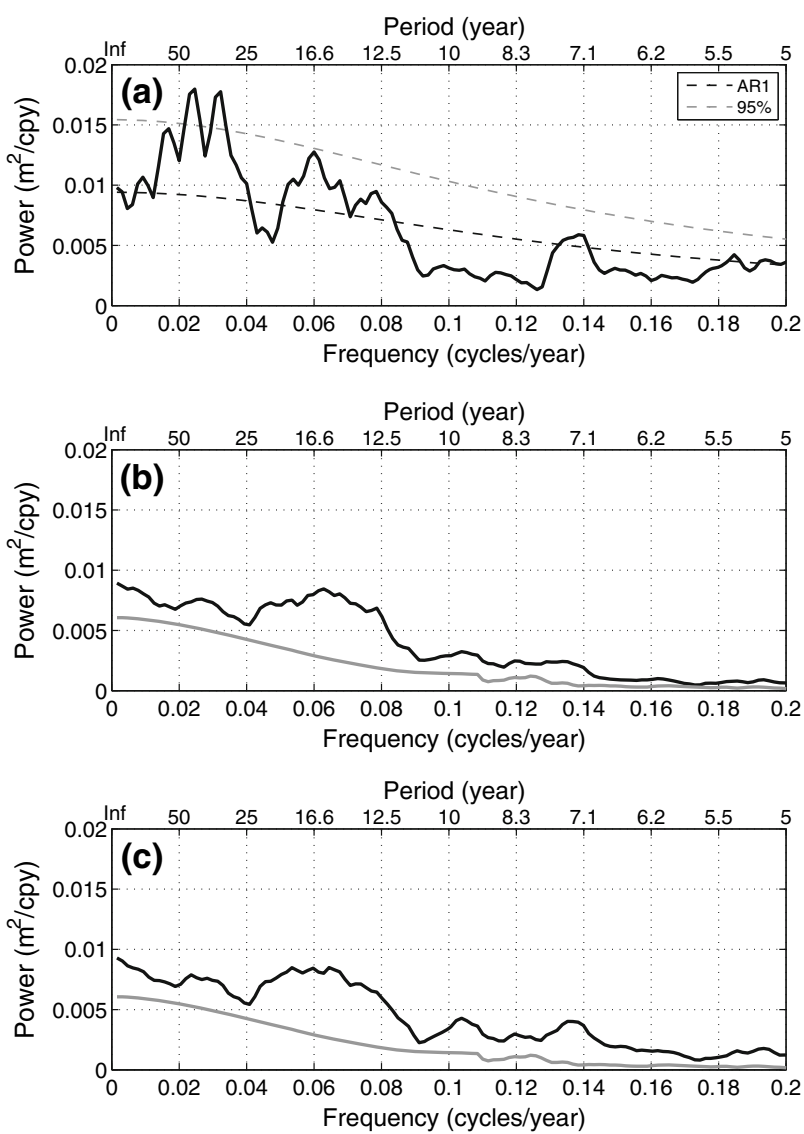

Fig. 13 Power spectrum of winter (DJFM) SSH anomalies averaged over $34^{\circ}-43^{\circ} \mathrm{N}, 140^{\circ} \mathrm{E}-180^{\circ}$ from (a) the CCSM2, and the Rossby wave model hindcast driven by (b) combination of CCSM2 wind stress curl response and whitened forcing patterns, and (c) combination of CMLM-E wind stress curl response and whitened forcing patterns. The gray lines in (b) and (c) are the Rossby wave model hindcast driven by the whitened forcing pattern alone. Note that (a) is reproduced from the Fig. 13b of Kwon and Deser (2007). The best-fit AR1 spectrum and $95 \%$ significant level with respect to the AR1 spectrum are plotted with dashed lines in (a)

\section{Conclusions}

The wintertime (JFM) response of the coupled atmosphere-ocean mixed layer system to geostrophic OHFC anomalies in the Kuroshio Extension has been examined by means of experiments with an AGCM coupled to an entraining ocean mixed layer model. In addition to the direct response, interaction with the tropics and the role of the extra-tropical ocean mixed layer were addressed through modifications of the experimental design.

The direct coupled ocean mixed layer-atmospheric circulation response to a positive OHFC anomaly in the Kuroshio Extension (experiment CMLM-E) consists of positive SST anomalies along the Kuroshio Extension and a baroclinic atmospheric response characterized by a lowlevel trough and upper-level ridge over the North Pacific. For an average SST anomaly of $3^{\circ} \mathrm{C}$ within the Kuroshio
Extension region, the response amplitudes over the North Pacific are approximately $2 \mathrm{hPa}$ for SLP and 10-20 m for Z250. In addition to the North Pacific response, an equivalent barotropic ridge response is found over the North Atlantic centered at $50^{\circ} \mathrm{N}$, with amplitudes $\sim 2 \mathrm{hPa}$ for SLP and $40 \mathrm{~m}$ for Z250. These atmospheric circulation anomalies drive a weak $\left(0.2-0.7^{\circ} \mathrm{C}\right)$ SST warming of the North Atlantic via perturbations to the surface turbulent energy flux.

When the ocean mixed layer is thermodynamically coupled to the atmosphere in the tropics as well as the extra-tropics (experiment CMLM-G), the tropical Pacific ITCZ shifts northward in response to oceanic warming along the Kuroshio Extension. The meridional displacement of the ITCZ generates a PNA-like atmospheric response that includes an equivalent barotropic ridge over the North Pacific. This tropically induced teleconnection modifies the direct coupled atmospheric circulation response, reducing the surface trough and enhancing the upper level ridge over the North Pacific.

The uncoupled atmospheric circulation response to a positive SST anomaly along the Kuroshio Extension (experiment AGCM-E) is generally similar to the coupled response, except that the anomalous SLP trough over the North Pacific is confined to the western half of the basin in AGCM-E. This sensitivity of the North Pacific SLP response to the presence of an interactive ocean mixed layer was suggested to result from the artificial enhancement of the anomalous atmosphere-to-ocean net surface heat flux downstream of the Kuroshio Extension in AGCM-E (e.g., lack of reduced thermal damping) compared to CMLM-E. The atmospheric cooling that results from the net surface heat flux response drives a positive SLP anomaly that partially offsets the negative SLP anomaly that is a direct response to the warming along the Kuroshio Extension. This effect increases over time, such that by March the SLP trough response over the North Pacific is nearly absent in AGCM-E. This result may have implications for SST-forced AGCM experiments conducted in "perpetual mode" for which the month or season is kept fixed.

The AGCM, CMLM, and CCSM2 experiments are similar in terms of their wind stress curl responses despite differences in their SLP responses. This is due to that the tropically-induced portion of the SLP responses in CMLM$G$ has a larger spatial scale than the locally-induced SLP response, a factor which affects the wind stress curl via the Laplacian operator. This result has implications for decadal variability of the Pacific coupled ocean-atmosphere system to the extent that the North Pacific ocean gyre circulation is primarily driven by wind stress curl fluctuations.

The linear Rossby wave model driven by the combination of a wind stress curl response taken from CMLM-E 
and a white noise wind stress curl forcing pattern taken from CCSM2 (which resembles the leading EOF over the North Pacific) reproduces the quasi-decadal (15-20 year) oscillation evident in CCSM2. This result supports the conclusion of Kwon and Deser (2007) that the quasi-decadal variability in CCSM2 owes its existence primarily to two-way atmosphere-ocean coupling in the North Pacific. There is some suggestion that this mechanism may also be operating in nature (Qiu et al. 2007), and work is currently underway to investigate this issue further.

Acknowledgments We wish to acknowledge helpful discussions and technical support from many colleagues including D. Ferreira, J. Goodman, A. Phillips, and J. Yin. We gratefully acknowledge financial support from NOAA's Office of Global Programs (grant to C. Deser and Y.-O. Kwon). Y.-O. Kwon is also supported through the Claudia Heyman Fellowship of the WHOI Ocean Climate Change Institute.

\section{References}

Alexander MA (2010) Extratropical air-sea interaction, SST variability and the Pacific Decadal Oscillation (PDO). In: Sun D, Bryan F (eds) Climate dynamics: why does climate vary. AGU Monograph (in press)

Alexander MA, Deser C (1995) A mechanism for the recurrence of wintertime midlatitude SST anomalies. J Phys Oceanogr 25:122-137

Alexander MA, Blade I, Newman M, Lanzante JR, Lau N-C, Scott JD (2002) The atmospheric bridge: the influence of ENSO teleconnections on air-aea interaction over the global oceans. J Clim 15:2205-2231

Barsugli JJ, Battisti DS (1998) The basic effects of atmosphere-ocean thermal coupling on midlatitude variability. J Atmos Sci 55:477493

Berloff P, Hogg AM, Dewar W (2007) The turbulent oscillator: a mechanism of low-frequency variability of the wind-driven ocean gyres. J Phys Oceanogr 37:2363-2386

Bonan GB, Oleson KW, Vertenstein M, Levis S (2002) The land surface climatology of the Community Land Model coupled to the NCAR Community Climate Model. J Clim 15:3123-3149

Branstator G (2002) Circumglobal teleconnection, the jet stream waveguide, and the North Atlantic Oscillation. J Clim 15:1893-1910

Bretherton CS, Battisti DS (2000) An interpretation of the results from atmospheric general circulation models forced by the time history of the observed sea surface temperature distribution. Geophys Res Lett 27:767-770

Briegleb BP, Hunke EC, Bitz CM, Lipscomb WH, Holland MM, Schramm JL, Moritz RE (2004) The sea ice simulation of the Community Climate System Model, version two. NCAR Tech. Note NCAR/TN-45 + STR, $34 \mathrm{pp}$

Broccoli AJ, Dahl KA, Stouffer RJ (2006) Response of the ITCZ to Northern Hemisphere cooling. Geophys Res Lett 33:L01702. doi: 10.1029/2005GL024546

Cassou C, Deser C, Alexander MA (2007) Investigating the impact of reemerging sea surface temperature anomalies on the winter atmospheric circulation over the North Atlantic. J Clim 20:3510 3526

Cessi P, Primeau F (2001) Dissipative selection of low-frequency modes in a reduced-gravity basin. J Phys Oceanogr 31:127-137
Chiang JCH, Bitz CM (2005) Influence of high latitude ice cover on the marine Intertropical Convergence Zone. Clim Dyn 5:477496. doi:10.1007/s00382-005-0040-5

Chiang JCH, Cheng W, Bitz CM (2008) Fast teleconnections to the tropical Atlantic sector from Atlantic thermohaline adjustment. Geophys Res Lett 35:L07704. doi:10.1029/2008GL033292

Deser C, Alexander MA, Timlin MS (1999) Evidence for a winddriven intensification of the Kuroshio Current Extension from the 1970s to the 1980s. J Clim 12:1697-1706

Deser C, Magnusdottir G, Saravanan R, Phillips AS (2004) The effects of North Atlantic SST and sea ice anomalies on the winter circulation in CCM3. Part II: direct and indirect components of the response. J Clim 17:877-889

Deser C, Capotondi A, Saravanan R, Phillips AS (2006) Tropical Pacific and Atlantic climate variability in CCSM3. J Clim 19:2451-2481

Deser C, Tomas RA, Peng S (2007) The transient atmospheric circulation response to North Atlantic SST and sea ice anomalies. J Clim 20:4751-4767

Frankignoul C, Kestenare E (2002) The surface heat flux feedback. Part I: estimates from observations in the Atlantic and the North Pacific. Clim Dyn 19:633-647

Frankignoul C, Sennéchael N (2007) Observed influence of North Pacific SST anomalies on the atmospheric circulation. J Clim 20:592-606

Frankignoul C, Muller P, Zorita E (1997) A simple model of the decadal response of the ocean to stochastic wind forcing. J Phys Oceanogr 27:1533-1546

Gaspar P (1988) Modeling the seasonal cycle of the upper ocean. J Phys Oceanogr 18:161-179

Hendon HH, Hartmann DL (1982) Stationary waves on a sphere: Sensitivity to thermal feedback. J Atmos Sci 39:1906-1920

Hoskins BJ, Karoly DJ (1981) The steady linear response of a spherical atmosphere to thermal and orographic forcing. J Atmos Sci 38:1179-1196

Kalnay E et al (1996) The NCEP/NCAR 40-year reanalysis project. Bull Amer Meteor Soc 77:437-470

Kang SM, Held IM, Frierson DMW, Zhao M (2008) The response of the ITCZ to extratropical thermal forcing: idealized slab-ocean experiments with a GCM. J Clim 21:3521-3532

Kelly KA (2004) The relationship between oceanic heat transport and surface fluxes in the western North Pacific: 1970-2000. J Clim 17:573-588

Kiehl JT, Gent PR (2004) The community climate system model, version 2. J Clim 17:3666-3682

Kumar A, Hoeling MP (1998) Specification of regional sea surface temperature in atmospheric general circulation model simulations. J Geophys Res 103(D8):8901-8907

Kushnir Y, Robinson WA, Blade I, Hall NMJ, Peng S, Sutton R (2002) Atmospheric GCM response to extratropical SST anomalies: synthesis and evaluation. J Clim 15:2233-2256

Kwon Y-O, Deser C (2007) North Pacific decadal variability in the Community Climate System Model version 2. J Clim 20:24162433

Latif M, Barnett TP (1996) Decadal climate variability over the North Pacific and North America: dynamics and predictability. J Clim 9:2407-2423

Liu Z, Wu L (2004) Atmospheric response to North Pacific SST: the role of ocean-atmosphere coupling. J Clim 17:1859-1882

Liu Z, Liu Y, Wu L, Jacob R (2007) Seasonal and long-term atmospheric responses to reemerging North Pacific Ocean variability: a combined dynamical and statistical assessment. J Clim 20:955-980

Mantua NJ, Hare SR, Zhang Y, Wallace JM, Francis RC (1997) A Pacific interdecadal climate oscillation with impacts on salmon production. Bull Amer Meteor Soc 78:1069-1079 
Miller AJ, Cayan DR, White WB (1998) A westward-intensified decadal change in the North Pacific Thermocline and Gyre-scale circulation. J Clim 11:3112-3127

Neelin JD, Weng WJ (1999) Analytical prototypes for ocean atmosphere interaction at midlatitudes. Part I: coupled feedbacks as a sea surface temperature dependent stochastic process. J Clim 12:697-721

Newman M, Compo GP, Alexander MA (2003) ENSO-forced variability of the Pacific Decadal Oscillation. J Clim 16:38533857

Okumura YM, Deser C, Hu A, Timmermann A, Xie S-P (2009) North Pacific climate response to freshwater forcing in the subarctic North Atlantic: oceanic and atmospheric pathways. J Clim 22:1424-1445

Park S, Deser C, Alexander MA (2005) Estimation of the surface heat flux response to sea surface temperature anomalies over the global oceans. J Clim 18:4582-4599

Peng S, Robinson WA (2001) Relationships between atmospheric internal variability and the responses to an extratropical SST anomaly. J Clim 14:2943-2959

Peng S, Whitaker JS (1999) Mechanisms determining the atmospheric response to midlatitude SST anomalies. J Clim 12:1393-1408

Peng S, Robinson WA, Hoerling MP (1997) The modeled atmospheric response to midlatitude SST anomalies and its dependence on background circulation states. J Clim 10:971-987

Pierce DW, Barnett TP, Schneider N, Saravanan R, Dommenget D, Latif M (2001) The role of ocean dynamics in producing decadal climate variability in the North Pacific. Clim Dyn 18:51-70

Qiu B (2000) Interannual variability of the Kuroshio Extension system and its impact on the wintertime SST field. J Phys Oceanogr 30:1486-1502

Qiu B (2003) Kuroshio Extension variability and forcing of the Pacific decadal oscillations: responses and potential feedback. J Phys Oceanogr 33:2465-2482

Qiu B, Schneider N, Chen S (2007) Coupled decadal variability in the North Pacific: an observationally constrained idealized model. J Clim 20:3602-3620

Saravanan R, McWilliams JC (1998) Advective ocean-atmosphere interaction: an analytical stochastic model with implications for decadal variability. J Clim 11:165-188

Schneider N, Cornuelle BD (2005) The forcing of the Pacific Decadal Oscillation. J Clim 18:4355-4373

Schneider N, Miller AJ (2001) Predicting Western North Pacific Ocean Climate. J Clim 14:3997-4002
Seager R, Kushnir Y, Naik NH, Cane MA, Miller J (2001) Winddriven shifts in the latitude of the Kuroshio-Oyashio Extension and Generation of SST anomalies on decadal timescales. J Clim 14:4249-4265

Sutton R, Mathieu PP (2002) Response of the atmosphere-ocean mixed layer system to anomalous ocean heat flux convergence. Quart J Roy Meteor Soc 128:1259-1275

Tanimoto Y, Nakamura H, Kagimoto T, Yamane S (2003) An active role of extratropical sea surface temperature anomalies in determining anomalous turbulent heat flux. J Geophys Res 108(C10):3304. doi:10.1029/2002JC001750

Trenberth KE, Branstator GW, Karoly D, Kumar A, Lau N-C, Ropelewski C (1998) Progress during TOGA in understanding and modelling global teleconnections associated with tropical sea surface temperatures. J Geophys Res 103(C7):14,291-14324

Vimont DJ (2005) The contribution of the interannual ENSO cycle to the spatial pattern of decadal ENSO-like variability. J Clim 18:2080-2092

Vivier F, Kelly KA, Thompson L (2002) Heat budget in the Kuroshio Extension region: 1993-1999. J Phys Oceanogr 32:3436-3454

Wallace JM, Grutzler DS (1981) Teleconnections in the geopotential height field during the Northern Hemisphere winter. Mon Wea Rev 109:784-812

Wu L, Liu Z (2005) North Atlantic decadal variability: air-sea coupling, oceanic memory, and potential northern hemisphere resonance. J Clim 18:331-349

Wu L, Li C, Yang C, Xie S-P (2008) Global teleconnections in response to a shutdown of the Atlantic meridional overturning circulation. J Clim 21:3002-3019

Xie SP, Kunitani T, Kubokawa A, Nonaka M, Hosoda S (2000) Interdecadal thermocline variability in the North Pacific for 1958-97: a GCM simulation. J Phys Oceanogr 30:2798-2813

Yulaeva E, Schneider N, Pierce DW, Barnett TP (2001) Modeling of North Pacific climate variability forced by oceanic heat flux anomalies. J Clim 14:4027-4046

Zhang Y, Wallace JM, Battisti DS (1997) ENSO-like interdecadal variability: 1900-93. J Clim 10:1004-1020

Zhong Y, Liu Z (2009) On the mechanism of pacific multidecadal climate variability in CCSM3: the role of the subpolar North Pacific ocean. J Phys Oceanogr 39:2052-2076

Zhong Y, Liu Z, Jacob R (2008) Origin of pacific multidecadal variability in Community Climate System Model, Version 3 (CCSM3): a combined statistical and dynamical assessment. J Clim 21:114-133 